\title{
Intertemporal asset pricing with bitcoin
}

\author{
Dimitrios Koutmos ${ }^{1}$. James E. Payne ${ }^{2}$
}

Published online: 9 July 2020

(c) Springer Science+Business Media, LLC, part of Springer Nature 2020

\begin{abstract}
This paper develops and tests an intertemporal regime-switching asset pricing model characterized by heterogeneous agents that have different expectations about the persistence and volatility of bitcoin prices. The model is estimated using daily bitcoin price data from 2013 until 2020 whereby three types of agents are considered: mean-variance optimizers, speculators and fundamentalists, respectively. While mean-variance optimizers trade on the basis of conditional first and second moments of the return distribution, speculators engage in trend chasing and buy when prices are rising and sell when prices are declining. Fundamentalists trade on the basis of fundamental factors that can impact the value of bitcoin. The fractions of agents engaging in one strategy over another shows statistically substantial variation during high and low bitcoin price volatility regimes. Estimation results reveal the following. First, unlike in traditional asset classes, there is evidence of mean-variance optimizers. Second, there is evidence of speculators who engage in 'bandwagon behavior' and buy bitcoins during price appreciations and sell bitcoins during price declines. Finally, there is evidence of fundamentalists who trade bitcoins when fundamental factors deviate from their long-run trends. Remarkably, these fundamentalists exhibit contrarian-type behaviors during low price volatility regimes while behaving more like fundamental traders during high price volatility regimes.
\end{abstract}

Keywords Asset pricing $\cdot$ Bitcoin $\cdot$ Heterogeneous agents $\cdot$ EGARCH $\cdot$ Hodrick-Prescott filter $\cdot$ Markov regime-switching

JEL Classification C5 $\cdot \mathrm{G} 10 \cdot \mathrm{G} 17 \cdot \mathrm{G} 19 \cdot \mathrm{G} 40$

Dimitrios Koutmos

dimitrios.koutmos@tamucc.edu

James E. Payne

jpayne2@utep.edu

1 Department of Accounting, Finance, and Business Law, College of Business, Texas A\&M

University - Corpus Christi, Corpus Christi, TX 78412, USA

2 College of Business Administration, The University of Texas at El Paso, El Paso, TX 79968, USA 


\section{Introduction}

A recurrent theme in the nascent literature seeking to model the behavior of bitcoin prices is that such prices are neither explainable on the basis of economic fundamentals nor are they entirely rational (Balcilar et al. 2017; Bouri et al. 2017; Li and Wang 2017; Pieters and Vivanco 2017; Koutmos 2018a). Bitcoin's unprecedented price volatility and its seemingly uncorrelated nature in relation to economic forces make it an attractive alternative asset for speculators and investors seeking to diversify their portfolios. Just in the midst of the European debt crisis, one bitcoin was worth about 13 USD (in January 2, 2013). In December 15, 2017, which was when bitcoin achieved its record high price, one bitcoin was worth over 19,600 USD—an arithmetic holding period return of well over $150,000 \%$ relative to early January of 2013 ! From this peak through early December 2018, bitcoin shed approximately $80 \%$ of its value before reaching another peak in June of 2019 where one bitcoin was worth over 11,800 USD. Since then, it has exhibited various significant price upswings and downswings and, currently in the midst of the global COVID-19 pandemic, one bitcoin is worth approximately 8000 USD.

This type of price volatility is exceptional compared to the return behavior of other traditional currencies and conventional asset classes and begs the question of what, or who, is driving bitcoin's price behavior. The increasing popularity of bitcoin yet our lack of empirical understanding as to what forces drive its price variation motivates this work.

This paper seeks to empirically model bitcoin prices by developing an intertemporal regimeswitching asset pricing model that characterizes the trading behaviors of heterogeneous agents who carry different attitudes and expectations about the persistence and volatility of bitcoin prices. Estimation results from experimental tests seeking to elicit heterogeneity in trading behaviors shows evidence supporting the notion that behavioral heterogeneity is a significant driver of bitcoin price behavior. This is a novel finding and departs from the conventional route taken in empirical literature thus far which seeks to regress bitcoin returns against theoreticallymotivated economic or technological factors that potentially underlie its price movements (Panagiotidis et al. 2018; Aalborg et al. 2019). Given that bitcoin is such an unusual asset, it is conceivable that its microstructure characteristics are driven by investors and a clientele base that is distinct from what can be found in traditional currency markets. Since the risk aversions of such investors differs fundamentally from those of traditional investors, it is not a complete surprise that bitcoin's value appears detached from established economic variables.

It may thus be of importance to instead focus on modeling the behavioral heterogeneity of bitcoin traders rather than relying on the usual economic factors that are familiarly reliable explanatory variables for traditional asset classes. From an econometric perspective, the asset pricing model posited herein provides a generalized and empirically tractable framework for exploring the trading behavior of mean-variance optimizers, speculators and fundamentalists, respectively. It is advantageous in that it can be applied to virtually any asset class for which price data is observable and it can accommodate an empiricist's desired selection of fundamental variables to motivate the buying and selling behavior of fundamentalists.

As is discussed later, the underpinnings for the posited framework align with asset pricing theory whereby in the statistical absence of speculators and fundamentalists the model reduces to the intertemporal capital asset pricing model of Merton (1980). The structure of the framework nests both the Sentana and Wadhwani (1992) and Cutler et al. (1990) models to provide a generalized framework for eliciting the trading behaviors of heterogeneous agents. Nesting the models is a novel econometric approach since conventional asset pricing tests tend to model speculators only in isolation (Hou and Li 2014; Wan and Yang 2017). 
An econometric innovation in the posited framework herein is that the demand function for fundamentalists depends on the extent to which fundamental factors deviate from their long-run trend. To model long-term trend trajectories in the proposed fundamental factors, the Hodrick-Prescott filtering technique is used (Hodrick and Prescott 1997). It can be shown that such deviations trigger buying and selling responses among fundamentalists.

Using daily bitcoin price data, this paper argues the following. First, that future research should consider behavioral trading patterns when attempting to explain bitcoin returns and not exclusively focus on familiar economic variables that have successfully explained the returns of conventional asset classes. Second, bitcoin returns experience regime shifts in their volatility dynamics and any statistical framework, such as ordinary least squares, which neglects to account for such shifts may yield parameter estimates that are unstable or lack robustness across random sampling periods. This latter point is the reason for the regime-shifting framework proposed herein and echoes the conclusions of $\mathrm{Li}$ and Wang (2017) who argue that "....it will be necessary to revisit the model (of bitcoin prices) at some future time and consider the possibility of multiple regime changes in exchange rate dynamics" (p. 59). The regime-switching framework also allows us to gauge the trading behaviors of heterogeneous agents across volatility regimes and to then make cross-regime comparisons.

In all, the findings of this paper can be summarized as follows. First, unlike findings focusing on conventional assets, such as equities or index funds (Bange 2000; Hou and $\mathrm{Li}$ 2014; Kinnunen 2014; Wan and Yang 2017), this paper shows that mean-variance optimizers are statistically present in driving bitcoin price movements, albeit their trading behavior is more pronounced during low bitcoin price volatility regimes. It may be the case that during relatively benign volatility periods, mean-variance optimizers are compensated in the form of expected returns per unit of conditional volatility. During high volatility regimes, however, expected returns from bitcoin are insufficient to compensate them for the exponential rise in price volatility. As is discussed further, during high volatility regimes, volatility risk, estimated from value-at-risk (VaR) and modified VaR measures, increase substantially during the high bitcoin price volatility regimes. Sharpe and modified Sharpe ratio computations also show a deterioration in risk-adjusted returns during the high volatility regime periods. This finding may be a reason why mean-variance optimizers are virtually absent during the high volatility regime.

Second, as what is found when exploring traditional asset classes, it can be shown that speculators are an important driving force behind bitcoin price movements. Their behavior is akin to the so-called 'bandwagon effect' whereby they buy more bitcoins when prices appreciate and sell bitcoins when prices decline. Thus, although bitcoin's uncorrelated nature with the state of economy is alluring to investors seeking alternative assets, it is not so different in the sense that 'bandwagon behavior' does drive its price movements (Baur et al. 2018). The fact that experimental tests herein indicate that speculators are consistently present in both low and high bitcoin price volatility regimes serves as a cautionary note to investors. This is because when speculative pressures are highly infused within asset prices, the value of those assets can, at any time, swiftly change regardless of their fundamental or true value (Shiller 1984, 2000).

Finally, fundamentalists are shown to be a strong driving force behind bitcoin price movements in both high and low volatility regimes. Specifically, when microstructure measures which impact bitcoin's value deviate from their long-run trajectory, they buy or sell bitcoins. Remarkably, during low volatility regimes, fundamentalists behave very much like contrarians. During the low volatility regime, when microstructure measures that have a positive impact on bitcoin's value increase at a greater rate than their long-term trajectory, 
fundamentalists actually sell bitcoins. Conversely, during high volatility regimes, fundamentalists behave more like fundamentalists. Thus, during the high volatility regime, when microstructure measures that have a positive impact on bitcoin's value increase at a greater rate than their long-term trajectory, fundamentalists buy bitcoins. Cross-regime comparisons of the findings show that fundamentalists act like contrarians during low volatility regime periods while acting more like fundamentalists during high volatility regime periods. Perhaps a reason for this behavior is that fundamentalists seek to capitalize on bitcoin returns during high volatility regimes when prices are likely to respond (more) positively to favorable movements in fundamental measures while maintaining a contrarian stance during periods of relatively stable prices.

These findings are a step in answering the question of what, or who, drives bitcoin price movements. From a theoretical perspective, they provide a reason for why the extant literature cannot decipher what factors, if any, determine bitcoin's price movements. The findings herein encourage future research into methodologies which seek to detect behavioral trading patterns when attempting to explain bitcoin returns and not to exclusively focus on familiar economic variables that have successfully explained the returns of conventional asset classes. From an econometric perspective, the behavioral heterogeneity framework proposed herein can tractably be re-parameterized and fitted with an empiricist's desired fundamental variables to be applied to virtually any asset with an observable price series. Finally, the findings are of importance to regulators, economists, investors and vendors who accept bitcoins because they illustrate the high degree of noise trading that is infused within bitcoin prices.

This paper focuses exclusively on bitcoin given its popularity and liquidity. To date, there are over 2000 cryptocurrencies in existence (CoinMarketCap 2020). Presently, bitcoin is the most popular cryptocurrency and the most liquid. It has a market capitalization of over 100 billion USD and represents the majority of the total market capitalization of all cryptocurrencies.

The remainder of this paper is structured as follows. Section 2 describes the bitcoin price data and fundamental measures that serve as proxies for bitcoin's fundamental source of value. The Hodrick-Prescott filtering approach is also discussed in Sect. 2. Section 3 develops the behavioral heterogeneity framework and explains the demand behavior of each of the proposed heterogeneous agents. Section 4 discusses the Markov regime-switching model that is used to implement the behavioral heterogeneity model. The risk-return dynamics for the low and high volatility regimes are also discussed in Sect. 4. Section 5 discusses the findings. Finally, Sect. 6 provides concluding remarks.

\section{Data}

\subsection{Bitcoin prices}

To examine the extent to which heterogeneous trading behavior drives the price movements of bitcoin, this paper utilizes daily spot prices of bitcoin from April 28, 2013 until March 1, 2020 for a total of 2500 daily observations. Unlike conventional assets which trade only on weekdays, bitcoin trades on weekdays as well as weekends. This paper considers a sample range which includes weekend price data. ${ }^{1}$

\footnotetext{
${ }^{1}$ Empirical test results of the behavioral heterogeneity framework proposed herein excluding weekend price data are not tabulated for the sake of brevity but are available upon request. These test results yield conclusions that are qualitatively identical with those from the findings reported here which include weekend prices.
} 


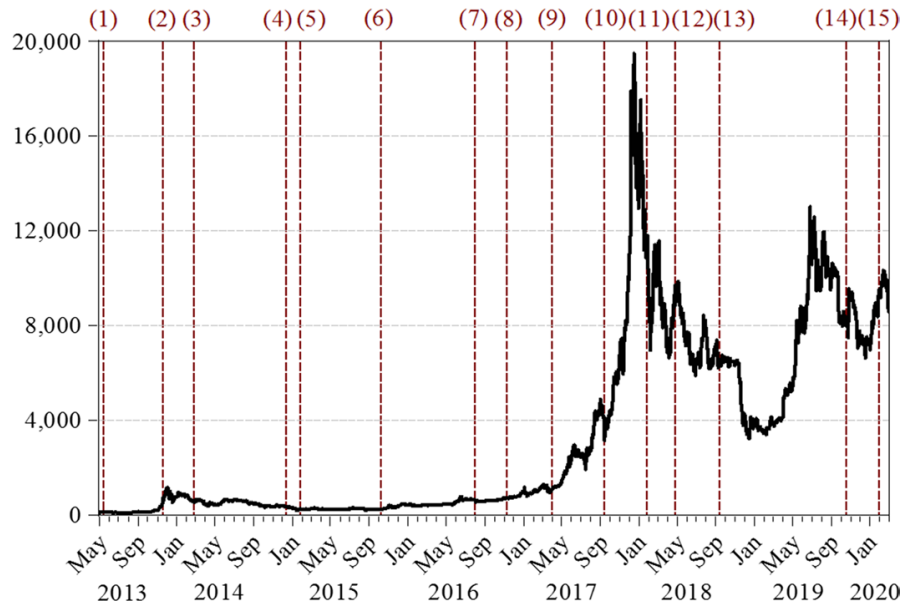

Fig. 1 Time series plot of bitcoin prices (in USD). This figure shows the time series plot for daily bitcoin prices (in USD) for the sample period April 28, 2013 until March 1, 2020. The vertical dashed lines numbered from (1) through (15) denote but a sample of the important socioeconomic and political events that transpired which impacted bitcoin users, exchanges and, ultimately, bitcoin prices. Their dates and the nature of the events are as follows: (1) May 14, 2013: The Department of Homeland Security obtains a seizure warrant against Mt. Gox, a bitcoin exchange based in Tokyo, Japan. (2) November 18, 2013: The US senate holds a hearing on bitcoin and digital currencies. (3) February 24, 2014: Mt. Gox suspends all trading and closes. (4) December 11, 2014: Microsoft begins accepting bitcoins. (5) January 26, 2015: Coinbase, the first regulated bitcoin exchange, opens inside US borders. (6) October 8, 2015: Gemini bitcoin exchange is launched. (7) August 2, 2016: Approximately 120,000 units of bitcoin (worth \$72 million at the time) are stolen from the exchange platform Bitfinex in Hong Kong. (8) November 9, 2016: Donald Trump is elected US president. (9) April 1, 2017: Japan declares that bitcoin may be used as legal tender. (10) September 15, 2017: China's three largest exchanges-BTC China, Huobi and OKCoin-have suspended local trading in anticipation of regulatory measures that will either stifle or altogether expunge bitcoin trading and transacting in China. (11) January 26, 2018: Coincheck, which is one of Japan's largest cryptocurrency OTC market, is hacked and over \$500 million of NEM are stolen or missing. This caused trading suspensions. (12) April 26, 2018: 17 million (out of the 21 million) bitcoins are mined. (13) September 14, 2018: Over $\$ 60$ million in bitcoin and two other cryptocurrencies are stolen from Zaif (Japanese-based exchange). (14) October 18, 2019: 18 million (out of the 21 million) bitcoins are mined. (15) January 30, 2020: The World Health Organization (WHO) declared the Coronavirus (COVID-19) outbreak to be a "public health emergency of international concern."

Figure 1 depicts a time series plot of daily spot prices for bitcoin (expressed in USD) for the full sample range. A sample of major events that impacted bitcoin's value are also indicated along with a brief description. Thus far, security breaches across some of the major cryptocurrency exchanges (such as Mt. Gox, Bitfinex and Coincheck, respectively), and the Chinese government's announcement to ban cryptocurrencies, are arguably the events that led to the highest volatility and price declines in bitcoin throughout the history which this cryptocurrency has been circulating and trading. The recent global COVID-19 pandemic may also see further declines in bitcoin's price, as investors make a flight-to-safety and hold less volatile assets in their investment accounts.

Events such as these also provide some support for the notion that structural breaks are inherent within the time series behavior of bitcoin returns - a feature in the data that can lead to strong time-dependence in the signs and statistical magnitudes of coefficient estimates (Thies and Molnar 2018). 


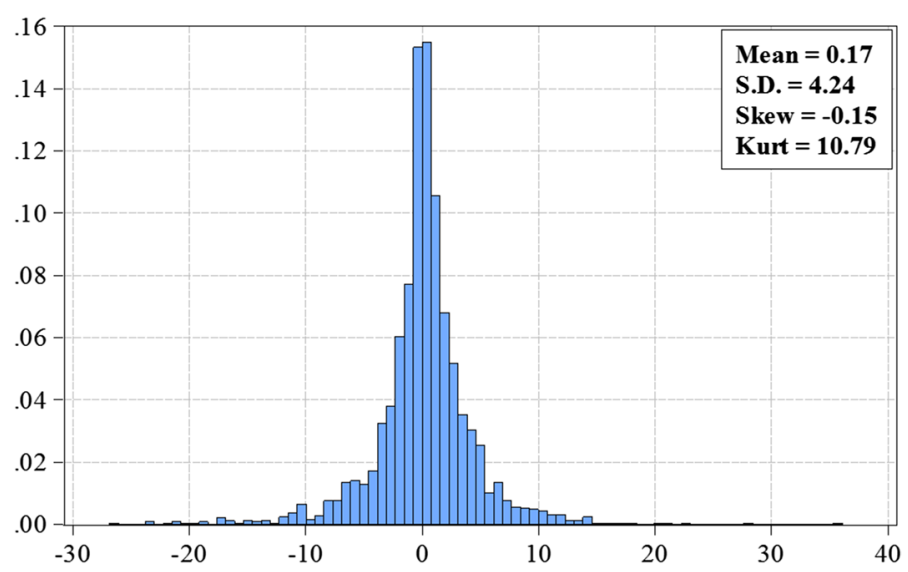

Fig. 2 Relative frequency distribution of daily logarithmic bitcoin returns. This figure shows a relative frequency distribution of daily logarithmic bitcoin returns for the sample period April 28, 2013 until March 1, 2020. The vertical axis denotes relative frequencies while the horizontal axis denotes bitcoin returns. The mean, standard deviation (S.D.), skewness (Skew.) and kurtosis (Kurt.), respectively, for logarithmic bitcoin returns over the sample period are also tabulated

As is discussed further in Sect. 4, this paper shows that bitcoin returns have distinct price volatility regimes which exhibit statistically significant differences in risk-return tradeoffs for investors. This result is also a likely reason why extant findings, such as those mentioned earlier in the introduction, cannot determine whether a set of theoretically motivated variables, economic in nature or otherwise, are significant in explaining bitcoin prices.

The relative frequency distribution of sampled daily logarithmic bitcoin returns, depicted in Fig. 2, is further informal demonstration of the large degree of dispersion in bitcoin price movements. It espouses the notion that distinct volatility regimes are inherent in the price data whereby conventional econometric tools, such as ordinary least squares, can generate unstable coefficient estimates, or, estimates that are strongly time-dependent.

\subsection{Fundamental factors and Hodrick-Prescott filtering}

This paper proposes a behavioral heterogeneity framework to model heterogeneous agents' trading behavior. The framework, discussed in Sect. 3, posits the existence of three types of agents: mean-variance optimizers, speculators and fundamentalists, respectively. While mean-variance optimizers consider returns and volatility risks, speculators make trading decisions on the basis of past prices and can engage in 'bandwagon behavior' when they buy bitcoins during recent price increases and sell bitcoins during recent price declines. In contrast to these two agents, fundamentalists make decisions on the basis of fundamental factors that likely impact the intrinsic value of bitcoin.

Despite bitcoin having a longer history in relation to other cryptocurrencies, it is still a novel asset and it will potentially take years, with a richer data experience, to better understand its fundamental value. This notwithstanding, bitcoin traders have a large degree of publicly available data at their disposal since, as is consistent with the underlying 

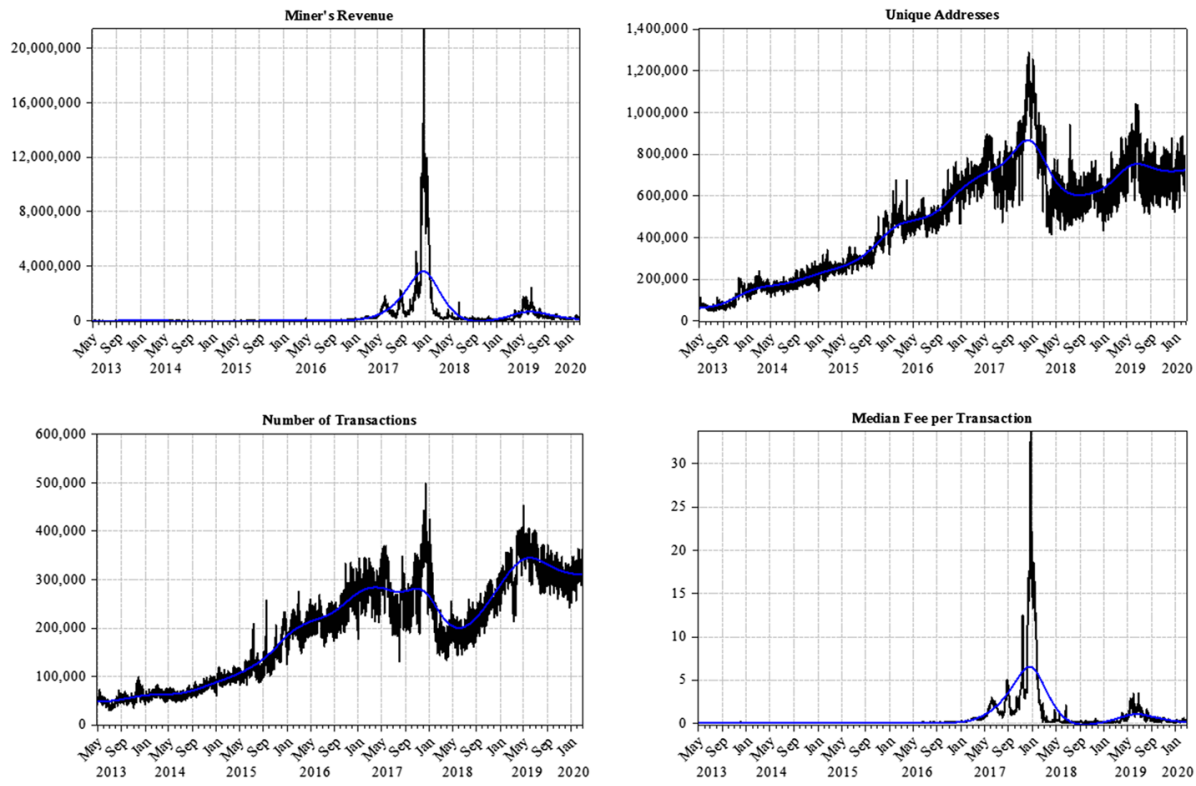

Fig. 3 Time series plots of fundamental factors with Hodrick-Prescott trend lines. This figure shows time series plots for bitcoin miners' revenue (in USD), number of unique bitcoin addresses, number of transactions involving bitcoin and the median fee per bitcoin transaction (in USD), respectively. Hodrick-Prescott trend lines (in blue) are estimated from (1) and (2). This data is updated daily and publicly available at https ://www.quandl.com. More information and real-time data updates are available at https://blockchain.info (Color figure online)

philosophy inherent in its distributed ledger design, transparency is an important feature of bitcoin that can ensure its continued existence in the years to come (Brandvold et al. 2015).

This paper makes use of four fundamental variables that are used by traders, and which are publicly available, in order to gauge the intrinsic value of bitcoin: miners' revenue, unique bitcoin addresses, number of transactions, and the median fee per transaction (in USD), respectively. These four factors are selected because they are important components within bitcoin's microstructure and whereby shifts in these factors can ultimately lead to changes in bitcoin's fundamental value.

Figure 3 shows time series plots for each of the four fundamental factors and we discuss them, in turn, here. Miners' revenue is expressed in USD and reflects the total compensation miners receive to mine increasingly scarcer bitcoins and to verify transactions. It reflects the profitability for miners and is computed as follows: (number of bitcoins mined per day + transaction fees) $*$ market price. ${ }^{2}$ As mining revenues increase, it indicates growing demand for miners' services and a growing market price for bitcoin.

\footnotetext{
${ }^{2}$ Böhme et al. (2015) discuss more the microstructure characteristics of bitcoin and the role and incentives for miners in mining bitcoins and verifying transactions. Many publicly available "bitcoin mining profitability calculators" are accessible online. These allow miners (or would-be miners) to compute their expected revenues based on variables such as bitcoin difficulty, bitcoins per block, hashing power, computing power consumption, cost per $\mathrm{KW} / \mathrm{h}$ and cost of mining hardware, to name but a few variables. Here are just a few URLs of the many popular websites for computing expected revenues: www.whattomine.com, www.niceh ash.com/profitability-calculator, www.bitcoinx.com/profit and www.cryptocompare.com/mining/calculator.
} 
Unique bitcoin addresses are identifiers that represent a unique possible destination for a bitcoin payment. From an economic perspective, there is a 'network effect' associated with the creation of a unique address. Specifically, bitcoin becomes a more valuable asset (or currency) when more and more people are using it and exchanging it. It is akin to, say, online social networks like Twitter and Facebook. The more members and users there are, the more useful (or valuable) the network becomes.

From a time series data analysis perspective, the number of bitcoin transactions is akin to, say, trading volume for equities. The more trade volume (or bitcoin transactions), the more liquidity there is for investors (or bitcoin users). An increasing number of transactions means that more businesses and vendors, as well as customers and investors, are adopting bitcoin as a method of transacting.

The median fee per transaction reflects the average cost for a transaction for one user (for the transfer of bitcoins from one address to another). As the number of users and transactions increases, the work of miners becomes more critical as they serve to verify transactions in a timely manner and to keep the bitcoin network efficient and usable. With more transactions and users, we expect to see higher network and transaction fees.

These four fundamental factors are important components within bitcoin's microstructure whereby significant rises (declines) in any of these factors is generally a positive (negative) indication for the fundamental value of bitcoin. As the demand for bitcoin rises, ceteris paribus, we naturally expect to see a rise in the levels of these fundamental factors. In the behavioral heterogeneity model in Sect. 3, fundamentalists buy or sell bitcoins based on the extent to which the aforementioned fundamental factors deviate from their long-run trajectories. In order to model each fundamental factor's trajectory, the Hodrick and Prescott (1997) filter technique is used. This technique decomposes an observed variable into its trend and cycle components, respectively. In the case of this paper, the Hodrick-Prescott filter technique is applied to each of the aforementioned four $i$ fundamental factors, $\mathrm{F}_{i, t}{ }^{3}$

Given $T$ observations of $\mathrm{F}_{i, t}$, the trend growth component, $g_{t}$, can be computed as

$$
\min _{\left\{g_{t}\right\}_{t=-1}^{T}}\left\{\sum_{t=1}^{T}\left(\mathrm{~F}_{t}-g_{t}\right)^{2}+\lambda \sum_{t=1}^{T}\left[\left(g_{t}-g_{t-1}\right)-\left(g_{t-1}-g_{t-2}\right)\right]^{2}\right\}
$$

As the smoothness penalty $\lambda \rightarrow 0, g_{t}$ is equivalent to the series $\mathrm{F}_{t}$. Conversely, when $\lambda \rightarrow \infty$, this method essentially becomes a regression on a linear time trend. As is discussed in Hamilton (2017), a closed-form expression for (1) can be written in vector notation whereby $\tilde{T}=T+2$ and $\underset{(T \times 1)}{\mathrm{F}}=\left(\mathrm{F}_{T}, \mathrm{~F}_{T-1}, \ldots, \mathrm{F}_{1}\right)^{\prime}$. The growth component is defined as $g=\left(g_{T}, g_{T-1}, \ldots g_{-1}\right)$ and, if we let $I_{T}$ denote the $(T \times T)$ identity matrix,

$$
\underset{(T \times \tilde{T})}{H}=\left[\begin{array}{cc}
I_{T} & 0 \\
(T \times T) & (T \times 2)
\end{array}\right]
$$

and

\footnotetext{
${ }^{3}$ The Hodrick-Prescott filter technique is universally applied in macroeconomic and financial time series analysis. Despite criticism, this technique is considered the workhorse in econometrics as a method for separating long-term trends from their transitory fluctuations. In the words of Ravn and Uhlig (2002, p. 371), "(the Hodrick-Prescott filter) has withstood the test of time and the fire of discussion remarkably well... although elegant new bandpass filters are being developed,... it is likely that the HP filter will remain one of the standard methods for de-trending.".
} 


$$
\left(\begin{array}{cccccccc}
1 & -2 & 1 & 0 & \cdots & 0 & 0 & 0 \\
0 & 1 & -2 & 1 & \cdots & 0 & 0 & 0 \\
\vdots & \vdots & \vdots & \vdots & \cdots & \vdots & \vdots & \vdots \\
0 & 0 & 0 & 0 & \cdots & -2 & 1 & 0 \\
0 & 0 & 0 & 0 & \cdots & 1 & -2 & 1
\end{array}\right)
$$

whereby the solution to (1) can be expressed as

$$
g^{*}=\left(H^{\prime} H+\lambda Q^{\prime} Q\right)^{-1} H^{\prime} \mathrm{F}=A * \mathrm{~F}
$$

The extracted trend growth component, $g^{*}$, for a given date $t$ is therefore a linear function of the entire set of $\mathrm{F}$ observable across all dates.

For each of the fundamental factors, F, in Fig. 3, the Hodrick-Prescott filter is also shown and reflects the long-run growth component, or, trajectory, for each of the factors. Positive 'shocks' in the factors, or, (transitory) rises above their growth component, likely indicate (transitory) surges in bitcoin's popularity as a medium of exchange and the demand for miners' services. This translates into (transitory) rises in the fundamental value of the bitcoin network. Conversely, negative 'shocks' in the factors, or, (transitory) declines below their growth component, likely indicate (transitory) contractions in the fundamental value of the bitcoin network.

\section{Modeling heterogeneous agents}

This paper elucidates upon the forces driving bitcoin price variations by modeling the trading heterogeneity of three types of behaviorally-driven heterogeneous agents: mean-variance optimizers, speculators, and fundamentalists, respectively. The framework extends theoretically the work of Merton (1980), Shiller (1984), Cutler et al. (1990), Sentana and Wadhwani (1992), Nofsinger and Sias (1999), Guo and Ou-Yang (2014) and Zhang and Zhang (2015) in order to provide an econometric framework for modeling heterogeneity which can be applied to virtually any asset class for which prices are observable.

The first group of agents are referred to as mean-variance optimizers. They trade seeking to maximize their expected mean-variance utility (Nakamura 2015). The demand for bitcoins by mean-variance optimizers, $M V$, is defined as

$$
M V_{t}=\left[E_{t-1}\left(R_{t}\right)-r_{f}\right] /\left(\theta \sigma_{t}^{2}\right) ; \theta>0 \text { or } \theta<0
$$

whereby $M V_{t}$ is the fraction of bitcoins they hold at time $t . E_{t-1}\left(R_{t}\right)$ is the expected return conditional on information available as of $t-1$ while $r_{f}$ denotes the risk-free rate. ${ }^{4}$ The

\footnotetext{
${ }^{4}$ In conventional asset pricing tests, the risk-free rate (the holding period yield on short-term government treasuries) is usually used as a benchmark to compare the returns on risky assets, such as equities or index funds. Subtracting the risk-free from the returns of risky assets is consistent with the economic notion that investors can either invest in risky assets or risk-free assets (or some combination of both). Investors holding risky assets forgo returns from risk-free assets and, therefore, the risk-free rate serves as a benchmark for the opportunity cost of capital. For this paper, the holding period return for the 1-month Treasury bill is used as a proxy for the risk-free rate, $r_{f}$. Data is obtained from Professor Kenneth French's publicly available online data library: http://mba.tuck.dartmouth.edu/pages/faculty/ken.french/data_library.html. Weekend data for the risk-free rate is interpolated using a moving average smoothing approach that fits the weekday data.
} 
coefficient of relative risk aversion is denoted by $\theta$ and, consistent with theoretical postulations should be positive and significant to support the notion of a positive risk-return tradeoff. The conditional variance of bitcoin returns at time $t$ is denoted by $\sigma_{t}^{2}$. If we assume that $\theta$ is positive, although the bitcoin price data ultimately decide the sign and significance of this coefficient, the product of $\theta \sigma_{t}^{2}$ represents the risk premium at time $t$. The demand for bitcoins by mean-variance optimizers is sensitive to volatility risk, $\sigma_{t}^{2}$, whereby their demand for bitcoins rises when their expected returns, $E_{t-1}\left(R_{t}\right)-r_{f}$, also rise.

The second group of agents are referred to as speculators. Their demand for bitcoins, Spec, is determined by past returns and is defined as

$$
\text { Spec }_{t}=\psi\left(R_{t-1}-r_{f}\right) ; \psi>0 \text { or } \psi<0
$$

whereby $\operatorname{Spec}_{t}$ is the fraction of bitcoins they hold at time $t$. Their behavior is speculative in the sense that it is driven solely by past returns, $R_{t-1}$, and whereby the coefficient $\psi$ reveals the direction of their trading behavior. If $\psi$ is positive, it shows that speculators are following trend-chasing, or, 'bandwagon' behaviors and buying during recent price increases and selling during recent price decreases. If $\psi$ is negative, it shows they are buying during recent price decreases and selling during recent price increases.

The third group of agents are referred to as fundamentalists. Their demand for bitcoins, Fund, is determined by the extent to which fundamental factors, $\mathrm{F}_{i}$, deviate from their respective long-run trajectories, $\tilde{F}_{i}$. As mentioned, there are four fundamental factors that are used; miners' revenue, unique bitcoin addresses, number of transactions, and the median fee per transaction, respectively. Thus, for $\mathrm{F}_{i}, i$ corresponds to these four fundamental factors, respectively, which serve as measures for bitcoin's value. The long-run trajectory for each of the $i$ factors, $\tilde{F}_{i}$, is estimated using the Hodrick-Prescott filtering procedure in (1) through (2). When $\mathrm{F}_{i}>\tilde{F}_{i}$ it indicates a positive (and favorable) 'shock' in the fundamental value of bitcoin, whereas when $\mathrm{F}_{i}<\tilde{F}_{i}$ it indicates a negative (and unfavorable) 'shock' in the fundamental value of bitcoin. To generalize, when fundamental factor $i, \mathrm{~F}_{i}$, is above its growth trend, $\tilde{F}_{i}$, it signifies sudden surges in the popularity of bitcoin and an unexpected growth in bitcoin's microstructure at large.

Since fundamentalists trade in accordance with the spread between fundamental factors and their growth trajectories, their demand for bitcoins, Fund, is defined as

$$
\text { Fund }_{t}=\pi\left(\mathrm{F}_{i, t-1}-\tilde{F}_{i, t-1}\right) ; \pi>0 \text { or } \pi<0
$$

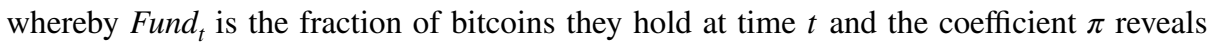
the direction of their trading behavior. If $\pi$ is positive, they behave consistent with a fundamentalist approach to trading - buying bitcoins during recent periods of positive shocks in its fundamental value and selling bitcoins during recent periods of negative shocks in its fundamental value. If, however, $\pi$ is negative, it indicates contrarian-type behaviors whereby they sell during recent periods of unexpected increases (positive shocks) in fundamental value and buy during recent periods of unexpected decreases (negative shocks) in fundamental value. ${ }^{5}$

\footnotetext{
${ }^{5}$ Rolling unit root tests (not tabulated for brevity) indicate that the spread between each fundamental factor with its growth rate, $\mathrm{F}_{i}-\tilde{F}_{i}$, is consistently stationary across time. Bitcoin returns, as well as their conditional volatility, are also stationary.
} 
For equilibrium between traders to hold in bitcoin markets, it is required that all bitcoins must be held by these three groups of heterogeneous agents,

$$
M V_{t}+\text { Spec }_{t}+\text { Fund }_{t}=1
$$

If we substitute (3) through (5) into (6), we can express this alternatively as

$$
\left[E_{t-1}\left(R_{t}\right)-r_{f}\right] /\left(\theta \sigma_{t}^{2}\right)+\psi\left(R_{t-1}-r_{f}\right)+\pi\left(\mathrm{F}_{i, t-1}-\tilde{F}_{i, t-1}\right)=1
$$

The model in (7) can be converted into a regression equation with a stochastic residual term by setting $r_{t}=R_{t-1}-r_{f}$ and $r_{t}+\varepsilon_{t}=E_{t-1}\left(R_{t}\right)-r_{f}$. When substituting these into (7), we have

$$
r_{t}=\theta \sigma_{t}^{2}-\psi\left(\theta \sigma_{t}^{2}\right)\left(r_{t-1}\right)-\pi\left(\theta \sigma_{t}^{2}\right)\left(\mathrm{F}_{i, t-1}-\tilde{F}_{i, t-1}\right)+\varepsilon_{t}
$$

Despite any (a)theoretical expectations, such as the coefficient $\theta$ is positive, parameterizations in (3) through (5) do not restrict the signs of the coefficients in any way. Moreover, and as is explained in Sect. 4, this allows them to possibly take on different signs during low and high bitcoin price volatility regimes.

It is expected that $\theta$ is positive, as this is consistent with the notion of a positive riskreturn tradeoff (Merton 1980). The term $-\psi\left(\theta \sigma_{t}^{2}\right)\left(r_{t-1}\right)$ implies that if speculators engage in trend chasing, or, 'bandwagon' trading behaviors, and thus the parameter $\psi$ is positive and significant, it induces a negative autocorrelation pattern in bitcoin returns that is proportional to the conditional variance, $\sigma_{t}^{2}$. Trend chasing behavior during periods of high volatility leads to a relatively larger degree of negative bitcoin return autocorrelation than, say, trend chasing during periods of low volatility. Conversely, a negative sign for $\psi$, indicating speculators buy during recent price decreases and sell during recent price increases, results in positive autocorrelation since we now have $-\left(-\psi\left(\theta \sigma_{t}^{2}\right)\left(r_{t-1}\right)\right)$. Finally, a positive sign for $\pi$, indicating fundamentalists are trading with fundamentals (buying when there is a positive shock and selling when there is a negative shock in fundamental value) leads to a positive value for $\pi$ and thus negative autocorrelation resulting from the term $-\pi\left(\theta \sigma_{t}^{2}\right)$. Conversely, if fundamentalists trade against fundamentals (buying when there is a negative shock and selling when there is a positive shock in fundamental value) this leads to a negative value for $\pi$ and thus positive autocorrelation resulting from now having the term $-\left(-\pi\left(\theta \sigma_{t}^{2}\right)\right)$.

The behavioral heterogeneity framework in (8) can be recast in a simplified form and, when including a coefficient to account for autocorrelation arising from non-synchronous trading or other market frictions (Lo and MacKinlay 1990), can be expressed as

$$
r_{t}=\beta_{0}+\beta_{1} \sigma_{t}^{2}+\left(\beta_{2}+\beta_{3} \sigma_{t}^{2}\right)\left(r_{t-1}\right)+\beta_{4} \sigma_{t}^{2}\left(\mathrm{~F}_{i, t-1}-\tilde{F}_{i, t-1}\right)+\varepsilon_{t}
$$

whereby $\beta_{1}=\theta$ and $\beta_{3}=-\psi(\theta)$. The constant term, $\beta_{0}$, is included as is econometrically a convention when performing asset pricing regression tests. It serves to account for other forces or information content not subsumed in the proposed explanatory variables. ${ }^{6}$ The

\footnotetext{
${ }^{6}$ From an econometric perspective, inclusion of a constant serves to ensure the model is unbiased, since the mean of the residuals is zero. From a practical application perspective, inclusion of a constant permits the fitted regression line to colloquially "find its own level" and to provide the best fit for the data. Generally speaking, inclusion of a constant provides less inflated test statistics which make for more conservative economic conclusions.
} 
autocorrelation coefficient is $\beta_{2}$ while $\beta_{4}=-\pi(\theta)$. Given its structure, the formulization in (9) fundamentally reduces to the Merton (1980) intertemporal capital asset pricing model in the absence of speculative traders and fundamentalists; $\beta_{3}=\beta_{4}=0$.

Since four fundamental factors are used to test for fundamentalists, $F$ takes the value of each of the four factors, respectively, for each separate estimation. Each regression estimation is designated as "model 1" (when F = miners' revenue), "model 2" (when F = unique addresses), "model 3" (when F = number of transactions), and "model 4" (when F = median fee per transaction), respectively (Koutmos 2018b). This is to distinguish between the estimations involving each of the fundamental factors and to enable cross-equation comparisons.

Finally, in order to implement (9), an estimate for the conditional variance of bitcoin returns, $\sigma_{t}^{2}$, is needed. For this purpose, the exponential generalized autoregressive conditional heteroskedasticity (EGARCH) model of Nelson (1991) is used,

$$
\ln \left(\sigma_{t}^{2}\right)=\delta_{0}+\delta_{1}\left|\frac{\varepsilon_{t-1}}{\sigma_{t-1}}\right|+\delta_{2}\left(\frac{\varepsilon_{t-1}}{\sigma_{t-1}}\right)+\delta_{3} \ln \left(\sigma_{t-1}^{2}\right)
$$

whereby the term $\left|\varepsilon_{t-1} / \sigma_{t-1}\right|$ represents the absolute value of the standardized innovations. Volatility asymmetry and persistence is indicated by the coefficients $\delta_{2}$ and $\delta_{3}$, respectively. $^{7}$

Figure 4 shows a time series plot of the conditional variance of bitcoin returns estimated from the EGARCH in (10). The 25th, 50th (median) and 75th percentiles, respectively, are also shown and support the notion that bitcoin can experience distinct volatility regimes in its price behavior. Perhaps the most significant events that led to the most uncertainty and volatility in bitcoin prices is the hacking of the various aforementioned exchanges, the Chinese government's ban on cryptocurrencies, and the recent COVID-19 global pandemic.

\section{Analytical framework}

\subsection{Markov regime-switching model}

It is plausible that behavioral forces in bitcoin markets can sway prices in different ways across volatility regimes. As shown in Fig. 4, periods of low versus high bitcoin price volatility can naturally trigger distinct responses by the heterogeneous agents proposed in (9).

\footnotetext{
7 Various symmetric and asymmetric GARCH-type volatility models are entertained (not reported for brevity). In terms of volatility dynamics, bitcoin returns exhibit volatility asymmetry, whereby negative return shocks lead to more volatility than positive return shocks of equal magnitude, as well as strong volatility persistence-an empirical finding observable from the returns of conventional assets such as stocks and index funds (Katsiampa 2017; Baur and Dimpfl 2018; Ardiar et al. 2019, among others). Various robustness tests that are not reported but available upon request show that the main conclusions of this paper are insensitive to $(a)$ the GARCH specification used to model volatility; $(b)$ the GARCH lag structure; $(c)$ the distributional assumptions regarding the GARCH error terms; and $(d)$ the conventional algorithms used to maximize the various typically-assumed log-likelihood functions.
} 


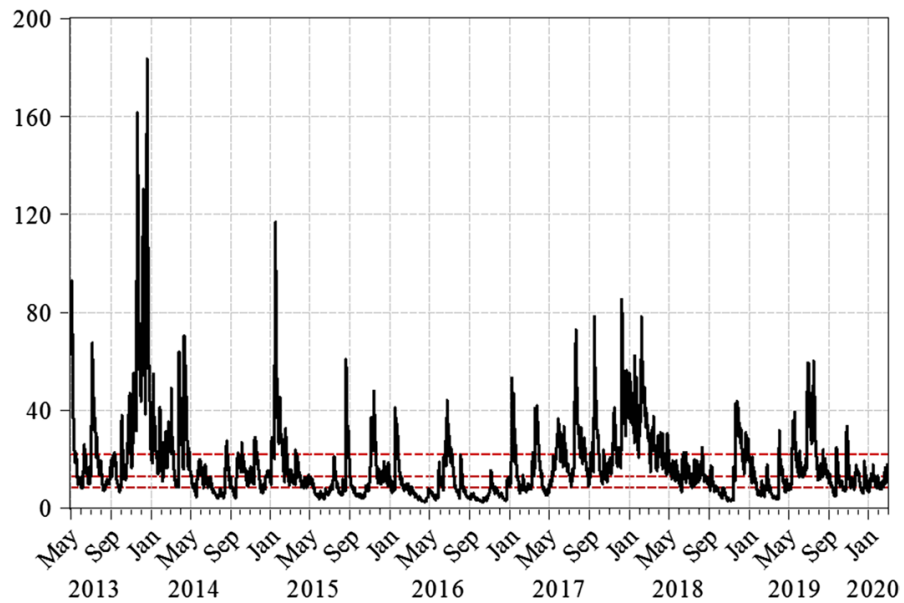

Fig. 4 Conditional variance of daily logarithmic bitcoin returns. This figure shows the conditional variance of daily logarithmic bitcoin returns for the sample period April 28, 2013 until March 1, 2020. The conditional variance is estimated using the EGARCH model in (10). The three horizontal dashed lines (in red) denote the 25th, 50th (median) and 75th percentiles, respectively (Color figure online)

Thus, utilizing an econometric framework, such as ordinary least squares, which neglects to distinguish between price volatility regimes can lead to an incomplete picture of the impact these heterogeneous agents exert.

In empirical asset pricing, the risk-return dynamics of various asset classes are very different across their price volatility regimes. This is the consequence of volatility clustering in financial markets - an empirical stylized fact whereby periods of price tranquility are interrupted by periods of statistically persistent turbulence (Kirchler and Huber 2007). From an investor psychology point of view, trading days associated with above average uncertainty and volatility, such as the when cryptocurrency exchanges are hacked, can exert an asymmetrically more powerful affect on their trading behaviors. This is consistent with the negativity bias in economic psychology which posits asymmetrically higher risk aversion shocks in the presence of negative news, or events, than to positive ones of similar magnitude.

This paper thus empirically tests for behavioral heterogeneity using a Markov regimeswitching approach. For the sake of discussing this approach, let us re-state (9) with notations indicating volatility regime states, $\mathrm{s}_{\mathrm{t}}$, as follows:

$$
r_{t}=\beta_{0, \mathrm{~s}_{\mathrm{t}}}+\beta_{1, \mathrm{~s}_{\mathrm{t}}} \sigma_{t}^{2}+\left(\beta_{2, \mathrm{~s}_{\mathrm{t}}}+\beta_{3, \mathrm{~s}_{\mathrm{t}}} \sigma_{t}^{2}\right)\left(r_{t-1}\right)+\beta_{4, \mathrm{~s}_{\mathrm{t}}} \sigma_{t}^{2}\left(\mathrm{~F}_{i, t-1}-\tilde{F}_{i, t-1}\right)+\varepsilon_{t}
$$

which will serve to test for behavioral trading patterns in low and high bitcoin price volatility regimes, respectively. Since bitcoin traders can behave differently in these two regimes, each of the coefficients in our behavioral heterogeneity model in (11) can thus take different values and exhibit distinct levels of significance depending on the state: 


$$
\begin{gathered}
\mathbb{A}_{s_{t}}=\left\{\begin{array}{ll}
\beta_{0,1} & \text { if } s_{\mathrm{t}}=1 \\
\beta_{0,2} & \text { if } \mathrm{s}_{\mathrm{t}}=2
\end{array} \quad \mathbb{B}_{s_{t}}= \begin{cases}\beta_{1,1} & \text { if } \mathrm{s}_{\mathrm{t}}=1 \\
\beta_{1,2} & \text { if } \mathrm{s}_{\mathrm{t}}=2\end{cases} \right. \\
\mathbb{C}_{s_{t}}=\left\{\begin{array}{ll}
\beta_{2,1} & \text { if } \mathrm{s}_{\mathrm{t}}=1 \\
\beta_{2,2} & \text { if } \mathrm{s}_{\mathrm{t}}=2
\end{array} \mathbb{D}_{s_{t}}= \begin{cases}\beta_{3,1} & \text { if } \mathrm{s}_{\mathrm{t}}=1 \\
\beta_{3,2} & \text { if } \mathrm{s}_{\mathrm{t}}=2\end{cases} \right. \\
\mathbb{E}_{s_{t}}= \begin{cases}\beta_{4,1} & \text { ifs } \\
\beta_{4,2} & \text { ifs } \mathrm{t}=2\end{cases}
\end{gathered}
$$

The evolution of the unobservable state variables in (11) and (12) thus follow a twostate Markov chain:

$$
\begin{array}{ll}
\operatorname{Pr}\left(\mathrm{s}_{\mathrm{t}}=1 \mid \mathrm{s}_{\mathrm{t}-1}=1\right)=\mathrm{p}_{11} & \operatorname{Pr}\left(\mathrm{s}_{\mathrm{t}}=2 \mid \mathrm{s}_{\mathrm{t}-1}=1\right)=\mathrm{p}_{12} \\
\operatorname{Pr}\left(\mathrm{s}_{\mathrm{t}}=1 \mid \mathrm{s}_{\mathrm{t}-1}=2\right)=\mathrm{p}_{21} & \operatorname{Pr}\left(\mathrm{s}_{\mathrm{t}}=2 \mid \mathrm{s}_{\mathrm{t}-1}=2\right)=\mathrm{p}_{22}
\end{array}
$$

whereby $\mathrm{p}_{11}+\mathrm{p}_{12}=\mathrm{p}_{21}+\mathrm{p}_{22}=1$. The notations $\operatorname{Pr}(\cdot)$ and $\mathrm{p}(\cdot)$ respectively represent the discrete probability set and a probability density function (Hamilton 1988; Phillips 1991; Shen 1994). The estimated values for $\mathrm{p}_{11}, \mathrm{p}_{12}, \mathrm{p}_{21}$ and $\mathrm{p}_{22}$ denote respective transition probabilities from going from one regime state to another (this is discussed more in Sect. 4.2).

The Markov chain in (13) is presumed to be independent of lagged bitcoin returns if we set conditions on $\mathrm{s}_{t-1}$. Estimating (11) using this approach is akin to drawing from a mixture of two normal distributions whereby the state, $\mathrm{s}_{t}$, decides which of the two normal densities are utilized to generate the model (Shen 1994). Bitcoin returns are thus assumed to switch between two states in accordance with their transition probabilities.

For simplicity, let us set $x_{t}=\left(1, \sigma_{t}^{2}, r_{t-1}, \sigma_{t}^{2} * r_{t-1}, \sigma_{t}^{2} *\left(\mathrm{~F}_{i, t-1}-\tilde{F}_{i, t-1}\right)\right)$ to represent the constant and the trading behaviors of each of the heterogeneous agents which serve as independent variables in (11). In addition, let us allow $\Phi_{\mathrm{s}_{t}}^{\prime}=\left(\mathbb{A}_{s_{t}}, \mathbb{B}_{s_{t}}, \mathbb{C}_{s_{t}}, \mathbb{D}_{s_{t}}, \mathbb{E}_{s_{t}}\right)$ to represent the set of coefficients in (11) that are estimated by the model.

In a more compact way, the model in (11) can thus be expressed as follows:

$$
r_{t+n}=x_{t} \Phi_{\mathrm{s}_{\mathrm{t}}}+\varepsilon_{t+n}
$$

Let us furthermore denote all the information available at time $t$ for each of the heterogeneous agents and for bitcoin returns with the capital letters $X_{t}$ and $Y_{t}$, respectively:

$$
\begin{aligned}
& X_{t}=\left(x_{1}, x_{2}, x_{3}, \ldots, x_{t}\right)^{\prime} \\
& Y_{t}=\left(y_{1}, y_{2}, y_{3}, \ldots, y_{t}\right)^{\prime}
\end{aligned}
$$

If we allow the parameter $\Omega$ to denote all the unknown parameters to be estimated in (11):

$$
\Omega=\left(\beta_{0,1}, \beta_{0,2}, \beta_{1,1}, \beta_{1,2}, \beta_{2,1}, \beta_{2,2}, \beta_{3,1}, \beta_{3,2}, \beta_{4,1}, \beta_{4,2}\right)
$$


and if we assume that the state, $\mathrm{s}_{\mathrm{t}}$, is known, we can specify the sample likelihood function conditional on a given state as follows:

$$
\mathrm{P}\left(y_{t} \mid \mathrm{s}_{\mathrm{t}} ; x_{t}, \Omega\right)=(1 / \sqrt{2 \pi \sigma}) \times \exp \left[\left(y_{t}-x_{t} \Phi_{\mathrm{s}_{\mathrm{t}}}\right)^{2} /-2 \sigma^{2}\right]
$$

whereby searching for the value of $\Omega$ which maximizes (16) is optimal.

The estimation for (11) through (16) consists of three parts. First, filter probabilities, $\operatorname{Pr}\left(\mathrm{s}_{\mathrm{t}} \mid Y_{t} ; X_{t}, \Omega\right)$, are estimated which utilize information available up until time $t$. Second, smooth probabilities, $\operatorname{Pr}\left(\mathrm{s}_{\mathrm{t}} \mid Y_{T} ; X_{T}, \Omega\right)$, are extracted using the filter probabilities. Whereas filter probabilities utilize information up to time $t$, smooth probabilities utilize the full data sample of ex post available information (up to time $T$ ) in order to make inferences about the historical regime states. Third, the smoothed probabilities are used in order to weight data and implement the regression (Hamilton 1990; Shen 1994). The weightings for the observations are computed as follows:

$$
\begin{aligned}
& y_{t}^{(j, *)}=y_{t} \times \sqrt{\operatorname{Pr}\left(\mathrm{s}_{\mathrm{t}}=j \mid Y_{T} ; X_{T}, \Omega\right)} \\
& x_{t}^{(j, *)}=x_{t} \times \sqrt{\operatorname{Pr}\left(\mathrm{s}_{\mathrm{t}}=j \mid Y_{T} ; X_{T}, \Omega\right)}
\end{aligned}
$$

The left-hand side of (17) represents the weighted observations and with the notation * in order to distinguish between the original observations. The superscript $j$ represents the present state.

Estimating (11) through (17) is advantageous because the risk-return dynamics of bitcoin's price behavior can display distinct statistical properties in each of the regimes (as is discussed in Sect. 4.2). This can yield interesting insights into the trading patterns of each of the heterogeneous agents and allows for cross-regime comparisons of their behaviors.

\subsection{Volatility regimes and their risk-return tradeoffs}

Before discussing the estimation results of (11), from an econometric standpoint, it is essential to scrutinize the statistical properties of bitcoin returns that fall under each of the regime states, $\mathrm{s}_{\mathrm{t}}$. As mentioned, this paper entertains four fundamental factors that serve as the basis for bitcoin's microstructure to model the behavior of fundamentalists; miners' revenue ("Model 1"), unique addresses ("Model 2"), number of transactions ("Model 3"), and median fee per transaction ("Model 4"), respectively. Given that (11) is estimated using the Markov regime-switching approach in (12) through (17) with each of the four aforementioned fundamental factors separately, it is possible to extract four separate smoothed probabilities which, a priori, are expected to be virtually identical. The smoothed probability of state $2, \mathrm{P}\left(\mathrm{s}_{\mathrm{t}}=2\right)$, which is the high volatility regime, is shown in Fig. 5 for each of the four models (that correspond with each of the four fundamental factors). Each of these four smoothed probabilities are illustrated in a stacked fashion. Their time series movements are 


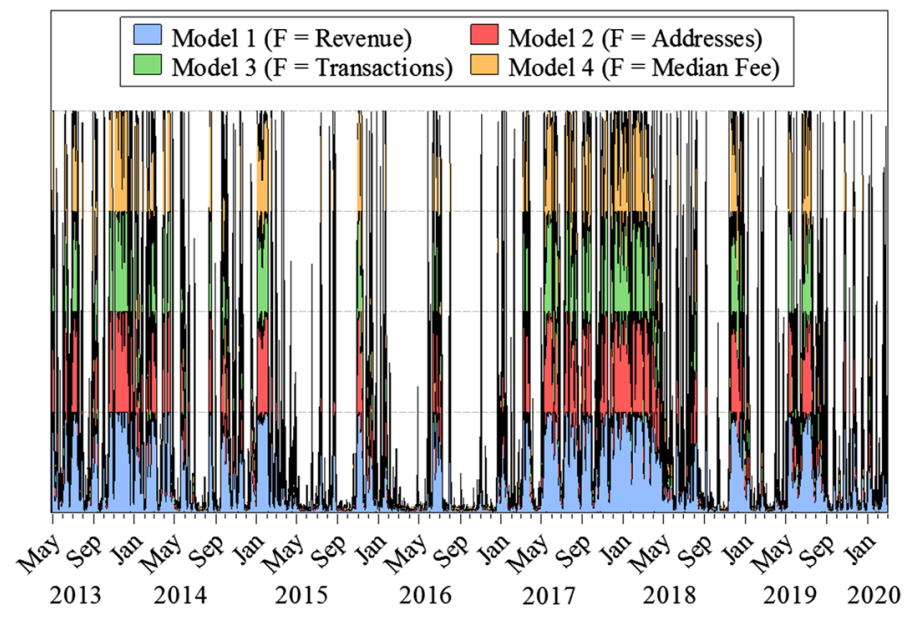

Fig. 5 Smoothed high volatility regime probabilities. This figure shows the time series of smoothed regime probabilities for the high bitcoin price volatility regime, $\mathrm{P}\left(\mathrm{s}_{\mathrm{t}}\right)=2$. These probabilities arise from estimation of the regime-switching behavioral heterogeneity framework in (11) that captures the trading behaviors of mean-variance optimizers, speculators and fundamentalists, respectively. For illustrative purposes, these regime probabilities are stacked whereby the horizontal dashed lines denote a probability of 1.00 for model 1 (in blue), model 2 (in red), model 3 (in green) and model 4 (in orange), respectively. The sample period is from April 28, 2013 until March 1, 2020 and each of the four models estimated uses a distinct fundamental factor, F, to capture the behavior of fundamentalists. The fundamental factors are miners' total revenue (model 1), number of unique addresses (model 2), number of transactions (model 3) and median fee per transaction in USD (model 4), respectively. Time series plots of each of these fundamental factors are illustrated in Fig. 3 (Color figure online)

virtually identical and, qualitatively, they uniformly identify regimes of high bitcoin price volatility.

From Fig. 5, it is evident that state 2, the high volatility regime, occurs with relatively less frequency than state 1 . However, it appears that high probabilities for state 2 cluster around certain events or time periods. This observation aligns with the notion of volatility clustering whereby large changes in an asset's price cluster around certain time periods, despite constituting a relatively smaller proportion of the overall sample.

Although smoothed regime probabilities represent the probability of being either in state 1 (low volatility regime) or state 2 (high volatility regime), it is important to make a distinction between the relative frequency of each regime's smoothed probability within the overall sample and the transition probabilities in (13). While the former is illustrated in Fig. 5 and shows that throughout the sample period there are more "low volatility regime" days than "high volatility regime" days, transition probabilities instead seek to answer the question, what is the probability of going from one regime state to another?

Given there are two states, there are four possibilities in terms of transitioning between low $\left(\mathrm{s}_{\mathrm{t}}=1\right)$ and high $\left(\mathrm{s}_{\mathrm{t}}=2\right)$ volatility regimes: $(i)$ Transitioning from a low $\left(\mathrm{s}_{\mathrm{t}-1}=1\right)$ to a low $\left(s_{t}=1\right)$ volatility regime; (ii) Transitioning from a low $\left(s_{t-1}=1\right)$ to a high $\left(s_{t}=2\right)$ 
Model 1

( $\mathrm{F}=$ Revenue)

\begin{tabular}{c|c}
$\mathrm{p}_{11}$ & $\mathrm{p}_{12}$ \\
$\operatorname{Pr}\left(\mathrm{s}_{\mathrm{t}}=1 \mid \mathrm{s}_{\mathrm{t}-1}=1\right) \approx 0.9043$ & $\operatorname{Pr}\left(\mathrm{s}_{\mathrm{t}}=2 \mid \mathrm{s}_{\mathrm{t}-1}=1\right) \approx 0.0957$ \\
\hline $\mathrm{p}_{21}$ & $\mathrm{p}_{22}$ \\
\hline $\operatorname{Pr}\left(\mathrm{s}_{\mathrm{t}}=1 \mid \mathrm{s}_{\mathrm{t}-1}=2\right) \approx 0.1732$ & $\operatorname{Pr}\left(\mathrm{s}_{\mathrm{t}}=2 \mid \mathrm{s}_{\mathrm{t}-1}=2\right) \approx 0.8268$
\end{tabular}

\begin{tabular}{c|c}
$\mathrm{p}_{11}$ & $\mathrm{p}_{12}$ \\
$\operatorname{Pr}\left(\mathrm{s}_{\mathrm{t}}=1 \mid \mathrm{s}_{\mathrm{t}-1}=1\right) \approx 0.8929$ & $\operatorname{Pr}\left(\mathrm{s}_{\mathrm{t}}=2 \mid \mathrm{s}_{\mathrm{t}-1}=1\right) \approx 0.1071$ \\
\hline $\mathrm{p}_{21}$ & $\mathrm{p}_{22}$ \\
\hline $\operatorname{Pr}\left(\mathrm{s}_{\mathrm{t}}=1 \mid \mathrm{s}_{\mathrm{t}-1}=2\right) \approx 0.1768$ & $\operatorname{Pr}\left(\mathrm{s}_{\mathrm{t}}=2 \mid \mathrm{s}_{\mathrm{t}-1}=2\right) \approx 0.8232$
\end{tabular}

\begin{tabular}{c|c}
$\mathrm{p}_{11}$ & $\mathrm{p}_{12}$ \\
$\operatorname{Pr}\left(\mathrm{s}_{\mathrm{t}}=1 \mid \mathrm{s}_{\mathrm{t}-1}=1\right) \approx 0.8953$ & $\operatorname{Pr}\left(\mathrm{s}_{\mathrm{t}}=2 \mid \mathrm{s}_{\mathrm{t}-1}=1\right) \approx 0.1047$ \\
\hline $\mathrm{p}_{21}$ & $\mathrm{p}_{22}$ \\
\hline $\operatorname{Pr}\left(\mathrm{s}_{\mathrm{t}}=1 \mid \mathrm{s}_{\mathrm{t}-1}=2\right) \approx 0.1745$ & $\operatorname{Pr}\left(\mathrm{s}_{\mathrm{t}}=2 \mid \mathrm{s}_{\mathrm{t}-1}=2\right) \approx 0.8255$
\end{tabular}

\begin{tabular}{c|c}
$\mathrm{p}_{11}$ & $\mathrm{p}_{12}$ \\
$\operatorname{Pr}\left(\mathrm{s}_{\mathrm{t}}=1 \mid \mathrm{s}_{\mathrm{t}-1}=1\right) \approx 0.8980$ & $\operatorname{Pr}\left(\mathrm{s}_{\mathrm{t}}=2 \mid \mathrm{s}_{\mathrm{t}-1}=1\right) \approx 0.1020$ \\
\hline $\mathrm{p}_{21}$ & $\mathrm{p}_{22}$ \\
\hline $\operatorname{Pr}\left(\mathrm{s}_{\mathrm{t}}=1 \mid \mathrm{s}_{\mathrm{t}-1}=2\right) \approx 0.1678$ & $\operatorname{Pr}\left(\mathrm{s}_{\mathrm{t}}=2 \mid \mathrm{s}_{\mathrm{t}-1}=2\right) \approx 0.8322$
\end{tabular}

Fig. 6 Transition probabilities. This figure shows transition probabilities computed from (13) illustrated in matrix form as shown in (18). These probabilities arise from estimation of the regime-switching behavioral heterogeneity framework in (11) that captures the trading behaviors of mean-variance optimizers, speculators and fundamentalists during low (regime 1) and high (regime 2) bitcoin price volatility regime states, $\mathrm{s}_{t}$, respectively. The sample period is from April 28, 2013 until March 1, 2020 and each of the four models estimated uses a distinct fundamental factor, F, to capture the behavior of fundamentalists. The fundamental factors are miners' revenue (model 1), number of unique addresses (model 2), number of transactions (model 3) and the median fee per transaction in USD (model 4), respectively. Time series plots of each of these fundamental factors are illustrated in Fig. 3

volatility regime; (iii) Transitioning from a high $\left(\mathrm{s}_{\mathrm{t}-1}=2\right)$ to a low $\left(\mathrm{s}_{\mathrm{t}}=1\right)$ volatility regime; (iv) Transitioning from a high $\left(\mathrm{s}_{\mathrm{t}-1}=2\right)$ to a high $\left(\mathrm{s}_{\mathrm{t}}=2\right)$ volatility regime.

These transition probabilities in (13) can thus be expressed in a $2 \times 2$ transition matrix as follows: 
Table 1 Pairwise correlations between high volatility smoothed regime probabilities

\begin{tabular}{lllll}
\hline & $\begin{array}{l}\text { Model 1 } \\
(\mathrm{F}=\text { Revenue })\end{array}$ & $\begin{array}{l}\text { Model 2 } \\
(\mathrm{F}=\text { Addresses })\end{array}$ & $\begin{array}{l}\text { Model 3 } \\
(\mathrm{F}=\text { Transactions })\end{array}$ & $\begin{array}{l}\text { Model 4 } \\
(\mathrm{F}=\text { Median Fee })\end{array}$ \\
\hline $\begin{array}{l}\text { Model 1 } \\
\text { (F= Revenue) }\end{array}$ & - & 0.9963 & 0.9981 & 0.9998 \\
$\begin{array}{l}\text { Model 2 } \\
\text { F = Addresses) }\end{array}$ & 0.9963 & - & 0.9988 & 0.9962 \\
$\begin{array}{l}\text { Model 3 } \\
\text { (F= Transactions) }\end{array}$ & 0.9981 & 0.9988 & - & 0.9981 \\
$\begin{array}{l}\text { Model 4 } \\
(\mathrm{F}=\text { Median Fee) }\end{array}$ & 0.9998 & 0.9962 & 0.9981 & - \\
\hline
\end{tabular}

This table shows pairwise correlations between the first difference in each of the time series of smoothed regime probabilities for the high bitcoin price volatility regime, $\mathrm{P}\left(\mathrm{s}_{\mathrm{t}}\right)=2$, when each of the respective fundamental factors are employed. These probabilities arise from estimation of the regime-switching behavioral heterogeneity framework in (11) that captures the trading behaviors of mean-variance optimizers, speculators and fundamentalists, respectively. Stationarity tests (not reported for brevity) indicate stationary behavior in the first differences of these smoothed regime probabilities. The sample period is from April 28, 2013 until March 1, 2020 and each of the four models estimated uses a distinct fundamental factor, F, to capture the behavior of fundamentalists. The fundamental factors are miners' revenue (model 1), number of unique addresses (model 2), number of transactions (model 3) and median fee per transaction in USD (model 4), respectively. Time series plots of each of these fundamental factors are illustrated in Fig. 3

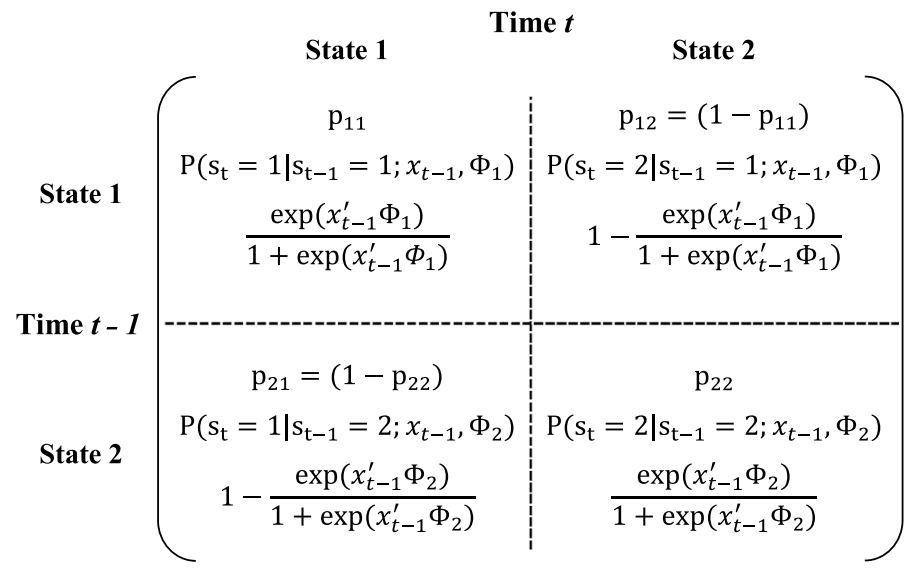

Figure 6 shows transition probabilities for (13) after estimating (11) with the Markov regime-switching framework in (12) through (17). Four transition probability matrixes are shown-each one corresponding to the fundamental factor that is used to empirically test (11); miners' revenue ("Model 1"), unique addresses ("Model 2"), number of transactions ("Model 3"), and median fee per transaction ("Model 4"), respectively.

The transition matrices for each of the four models reveal that $\mathrm{p}_{11}>\mathrm{p}_{12}$; the probability of going from $\mathrm{s}_{\mathrm{t}-1}=1$ to $\mathrm{s}_{\mathrm{t}}=1\left(\mathrm{p}_{11}\right)$ ranges from $89.29 \%$ ("Model 2") to $90.43 \%$ ("Model 1") while the probability of going from $\mathrm{s}_{\mathrm{t}-1}=1$ to $\mathrm{s}_{\mathrm{t}}=2\left(\mathrm{p}_{12}\right)$ ranges from $9.57 \%$ ("Model 1 ") to $10.71 \%$ ("Model 2"). Likewise, inspection of the lower quadrants of the transition matrices show $\mathrm{p}_{21}<\mathrm{p}_{22}$. In sum, these findings support the notion of volatility clustering for bitcoin returns (and volatility regimes); in the words of Mandelbrot (1963), large changes tend to be followed by large changes, of either sign, and small changes tend to be followed by small 


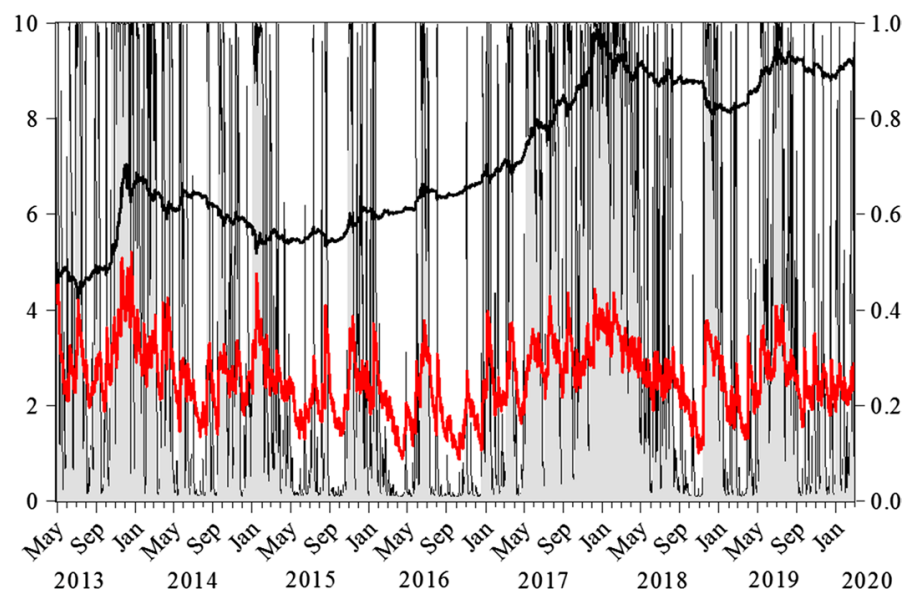

Fig. 7 Averaged high volatility regime probability. This figure shows an averaged time series for the smoothed high volatility regime probability (in grey and measured on the right axis). It is computed as an equal-weighted average of all the smoothed high volatility regime probabilities illustrated in Fig. 5 from the four models which utilize a distinct fundamental factor to capture the behavior of fundamentalist traders (models 1 through 4). The natural logarithm of the conditional price volatility of bitcoin returns, derived from the EGARCH in (10) and illustrated in levels in Fig. 4, is shown in red while the natural logarithm of bitcoin prices, illustrated in raw prices (in USD) in Fig. 1, is shown in black. The left axis here denotes natural logarithms and the sample period is from April 28, 2013 until March 1, 2020

Table 2 Risk-return statistics of bitcoin returns across volatility regimes

\begin{tabular}{llllllllr}
\hline Regime state, $\mathrm{s}_{\mathrm{t}}$ & Mean & Std.dev. & Skew. & Kurt. & VaR & $\begin{array}{l}\text { Modified } \\
\text { VaR }\end{array}$ & Sharpe & $\begin{array}{l}\text { Modified } \\
\text { Sharpe }\end{array}$ \\
\hline $\begin{array}{l}P\left(s_{t}=1\right), \\
\text { for } P \geq 0.95\end{array}$ & 0.1068 & 1.1426 & 0.0437 & 0.1851 & -2.1327 & -2.1233 & 0.0935 & 0.0503 \\
$\begin{array}{l}P\left(s_{t}=2\right), \\
\text { for } P \geq 0.95\end{array}$ & -0.4462 & 8.6129 & -0.0056 & 0.0527 & -17.3276 & -17.3816 & -0.0518 & -0.0257 \\
\hline
\end{tabular}

This table reports risk-return statistics of bitcoin returns for each of the volatility regimes. Given the high degree of correlation between each of the volatility regime probabilities from each of the four models used to capture the behavior of fundamentalists (models 1 through 4), this table computes risk-return statistics from an equal-weighted average of all the four regime probabilities. Table 1, for example, shows the pairwise correlations between the high volatility smoothed regime probabilities (in first differences) from each of the four models while Fig. 7 shows the averaged high volatility regime probability. Each of the four models is estimated using the regime-switching behavioral heterogeneity framework in (11) that captures the trading behaviors of mean-variance optimizers, speculators and fundamentalists, respectively. The sample period is from April 28, 2013 until March 1, 2020. Regime $1\left[P\left(s_{t}=1\right)\right]$ represents the low volatility regime while regime $2\left[P\left(s_{t}=2\right)\right]$ represents the high volatility regime. The statistics reported here are estimated from bitcoin returns associated with either $s_{t}=1$ or $s_{t}=2$ with a probability of greater than or equal to $0.95(P \geq 0.95)$, respectively. The value-at-risk (VaR) equation is discussed in footnote (9) while the modified VaR (MVaR) is computed from (19). Both the VaR and MVaR are expressed in percentages. The Sharpe ratio is discussed in footnote (9) while the modified Sharpe ratio is computed from (22) 
changes. This point is also ascertained by observing the high transition probabilities of $\mathrm{p}_{11}$ and $\mathrm{p}_{22}$, respectively, and although in all four models $\mathrm{p}_{11}>\mathrm{p}_{22}$, the transition probability for $\mathrm{p}_{22}$ is still quite high despite the fact that $\mathrm{s}_{\mathrm{t}}=1$ constitutes a larger segment of the overall sample.

From the transition probabilities computed in (13), we can also estimate the durations for each of the regime states (Hamilton 1989). Estimating durations help in approximating when a current regime state is likely to end. For example, using the transition probabilities in Fig. 6 for "Model 1" (when F = miners' revenue), the expected duration for the low volatility regime, $\mathrm{s}_{\mathrm{t}}=1$, is $1 /\left(1-\mathrm{p}_{11}\right) \approx 10$ trading days while for the high volatility regime, $\mathrm{s}_{\mathrm{t}}=2$, the expected duration is $1 /\left(1-\mathrm{p}_{22}\right) \approx 6$ trading days. ${ }^{8}$ Despite constituting a significantly smaller segment of the overall sample, as shown in Fig. 5, the expected duration for the high volatility regime is more than half that of the low volatility regime-testament to the high persistence in bitcoin price volatility.

Having explored the nature of the transition probabilities, it is vital to understand the risk-return characteristics of bitcoin returns which fall under each of the two volatility regimes. Doing so provides an understanding of each regime's investment environment and a context for the trading behaviors of the heterogeneous agents. Since we model (11) using four fundamental factors, F, separately, we now have four smoothed regime probabilities as shown in Fig. 5. As mentioned, the time series in these probabilities is virtually identical in distinguishing low from high volatility regimes and, as shown in Table 1, the pairwise correlations between each of the smoothed probabilities are no less than 0.9962 in any given case and, on average, are over 0.99 .

For the purposes of quantifying the risk-return environments for each of the volatility regimes, the smoothed regime probabilities in Fig. 5 are combined by taking an equalweighted time-series average of all four of them in order to produce a single regime probability that can serve as an indicator for regime shifts for (11). Figure 7 shows the averaged smoothed probability for the high volatility regime $\left(s_{t}=2\right)$ alongside the logarithm of bitcoin prices and the logarithm of the conditional variance for bitcoin returns. These three time series in Fig. 7 show that as the averaged high volatility regime probability approaches 1.00 , this corresponds with peaks in the price volatility of bitcoin returns.

Using the averaged smooth regime probability in Fig. 7, Table 2 reports the risk-return characteristics of the inferred low $\left(s_{t}=1\right)$ and high $\left(s_{t}=2\right)$ volatility regimes, respectively. In the low volatility regime, mean returns are $0.11 \%$ while in the high volatility regime mean returns are $-0.45 \%$. Computing value-at-risk $(\mathrm{VaR})$ for each of the regimes at the $95 \%$ confidence interval shows that $\mathrm{s}_{\mathrm{t}}=2$ (with a VaR of $-17.33 \%$ ) exposes investors to a higher degree of possible losses relative to $s_{t}=1$. Sharpe ratio calculations show a lower return per unit of volatility risk for $s_{t}=2$ relative to $s_{t}=1$. If we integrate higher moment risks into the Sharpe ratio and VaR computations, it can be shown that investors in the high volatility regime are not rewarded for the incremental multifaceted risks they must absorb. ${ }^{9}$

\footnotetext{
${ }^{8}$ The expected duration for the low volatility regime (state 1$)$ is $\sum_{k=1}^{\infty} k \times \mathrm{p}_{11}^{k-1}\left(1-\mathrm{p}_{11}\right)=1 /\left(1-\mathrm{p}_{11}\right)$ while for the high volatility regime (state 2$)$ it is $1 /\left(1-\mathrm{p}_{22}\right)$. More details are provided in Hamilton (1989, p.374).

9 The Sharpe ratio for bitcoin returns, $R_{t}$, is computed as $\left(R_{t}-r_{f}\right) / \sigma$ whereby $r_{f}$ denotes the risk-free rate (see footnote (4) for an explanation of $r_{f}$ ). The denominator for the Sharpe ratio is the standard deviation of bitcoin returns, $\sigma$. The $\mathrm{VaR}$ for bitcoin returns is calculated as follows: $\operatorname{VaR}=W(\mu \Delta t-n \sigma \sqrt{\Delta t})$ whereby $\mu$ is the mean return for bitcoin; $W$ is the value of the portfolio invested in bitcoin; $n$ is the number of standard deviations depending on the confidence level; $\sigma$ is the standard deviation of bitcoin returns; $\Delta t$ is the time window. More discussion and derivations for VaR and MVaR can be found in Signer and Favre (2002).
} 
Table 3 Testing for behavioral heterogeneity

\begin{tabular}{|c|c|c|c|c|c|}
\hline Regime & Coeff. & $\begin{array}{l}\text { Model } 1 \\
(\mathrm{~F}=\text { Revenue })\end{array}$ & $\begin{array}{l}\text { Model } 2 \\
\text { (F = Addresses) }\end{array}$ & $\begin{array}{l}\text { Model } 3 \\
\text { (F = Transactions) }\end{array}$ & $\begin{array}{l}\text { Model } 4 \\
(\mathrm{~F}=\text { Median Fee })\end{array}$ \\
\hline \multirow[t]{5}{*}{$\begin{array}{l}\mathrm{P}\left(\mathrm{s}_{\mathrm{t}}\right)=1 \\
\left\{\text { Low } \sigma^{2}\right\}\end{array}$} & $\beta_{0}$ & $\begin{array}{l}0.0492 * * \\
(2.178)\end{array}$ & $\begin{array}{l}0.0114 \\
(0.504)\end{array}$ & $\begin{array}{l}0.0121 \\
(0.118)\end{array}$ & $\begin{array}{l}-0.3422 \\
(-1.298)\end{array}$ \\
\hline & $\beta_{1}$ & $\begin{array}{l}1.4980 * * \\
(2.388)\end{array}$ & $\begin{array}{l}2.0893 * * * \\
(4.831)\end{array}$ & $\begin{array}{l}2.8341 * * * \\
(3.915)\end{array}$ & $\begin{array}{l}8.7811 * * * \\
(13.147)\end{array}$ \\
\hline & $\beta_{2}$ & $\begin{array}{l}0.0587 * * \\
(2.004)\end{array}$ & $\begin{array}{l}0.0515^{*} \\
(1.783)\end{array}$ & $\begin{array}{l}0.0315 \\
(0.246)\end{array}$ & $\begin{array}{l}0.2188 * * * \\
(4.173)\end{array}$ \\
\hline & $\beta_{3}$ & $\begin{array}{l}-7.5870^{* * * *} \\
(-8.256)\end{array}$ & $\begin{array}{l}-7.0820 * * * \\
(-13.874)\end{array}$ & $\begin{array}{l}-4.6870^{* * *} \\
(-9.451)\end{array}$ & $\begin{array}{l}-5.2405 * * * \\
(-7.710)\end{array}$ \\
\hline & $\beta_{4}$ & $\begin{array}{l}0.0033 \\
(0.931)\end{array}$ & $\begin{array}{l}0.1193 * * * \\
(3.258)\end{array}$ & $\begin{array}{l}0.2368 * * \\
(2.418)\end{array}$ & $\begin{array}{l}2.884 \\
(0.776)\end{array}$ \\
\hline \multirow[t]{5}{*}{$\begin{array}{l}\mathrm{P}\left(\mathrm{s}_{\mathrm{t}}\right)=2 \\
\left\{\text { High } \sigma^{2}\right\}\end{array}$} & $\beta_{0}$ & $\begin{array}{l}-0.4779 \\
(-1.108)\end{array}$ & $\begin{array}{l}-0.4682 \\
(-1.328)\end{array}$ & $\begin{array}{l}-0.4813 \\
(-1.114)\end{array}$ & $\begin{array}{l}-0.0818 \\
(-0.412)\end{array}$ \\
\hline & $\beta_{1}$ & $\begin{array}{l}1.9201 * \\
(1.638)\end{array}$ & $\begin{array}{l}1.6974 * \\
(1.796)\end{array}$ & $\begin{array}{l}1.8734 * \\
(1.883)\end{array}$ & $\begin{array}{l}0.0206 \\
(1.407)\end{array}$ \\
\hline & $\beta_{2}$ & $\begin{array}{l}0.2451 * * * \\
(3.129)\end{array}$ & $\begin{array}{l}0.2476^{*} \\
(1.910)\end{array}$ & $\begin{array}{l}0.2480 * * * \\
(2.887)\end{array}$ & $\begin{array}{l}0.2879 * * * \\
(6.255)\end{array}$ \\
\hline & $\beta_{3}$ & $\begin{array}{l}-3.3952 * * * \\
(-2.933)\end{array}$ & $\begin{array}{l}-3.3284 * * * \\
(-4.663)\end{array}$ & $\begin{array}{l}-3.5120 * * * \\
(-4.879)\end{array}$ & $\begin{array}{l}-3.8504^{* * * *} \\
(-4.001)\end{array}$ \\
\hline & $\beta_{4}$ & $\begin{array}{l}-0.0038 * * \\
(-2.114)\end{array}$ & $\begin{array}{l}-0.0168 * * \\
(-2.470)\end{array}$ & $\begin{array}{l}0.0032 \\
(0.147)\end{array}$ & $\begin{array}{l}-2783.2216^{* * *} \\
(-2.088)\end{array}$ \\
\hline
\end{tabular}

This table reports coefficient estimates for the regime-switching behavioral heterogeneity framework in (11) in order to test for the presence of mean-variance optimizers, speculators and fundamentalists, respectively. A Markov regime-switching approach, described in (12) through (17), is used to estimate the signs and statistical magnitudes of the coefficients for low (regime 1) and high (regime 2) bitcoin price volatility regime states, $\mathrm{s}_{t}$, respectively. The sample period is from April 28, 2013 until March 1, 2020 and each of the four models estimated uses a distinct fundamental factor, F, to capture the behavior of fundamentalists. The fundamental factors are miners' revenue (model 1), number of unique addresses (model 2), number of transactions (model 3) and median fee per transaction in USD (model 4), respectively. Time series plots of each of these factors are illustrated in Fig. 3. The reported coefficient estimates for $\beta_{1}, \beta_{3}$ and $\beta_{4}$ are scaled by factors of $\left(\times 10^{2}\right),\left(\times 10^{3}\right)$ and $\left(\times 10^{6}\right)$, respectively. Dilating the estimates with these scaling factors is solely for illustrative purposes, given the different magnitudes in values for each of the fundamental factors (this is why the coefficient $\beta_{4}$ for model 4 differs from the others). Test statistics are indicated in parentheses while significance at the $10 \%, 5 \%$ and $1 \%$ levels is denoted by $*, * *$ and $* * *$, respectively

In order to compute risk-return statistics while adjusting for departures from normality in the return series, which can account for crash risk (skewness) and tail risk (kurtosis), it is meaningful to estimate a modified $\mathrm{VaR}(\mathrm{MVaR})$ and modified Sharpe ratio to reflect such higher moment risks (Gregoriou and Gueyie 2003). The MVaR can be expressed as follows (using some of the same notation as the VaR in footnote (9)):

$$
\operatorname{MVaR}=W\left[\mu-\left\{z_{c}+\frac{1}{6}\left(z_{c}^{2}-1\right) S+\frac{1}{24}\left(z_{c}^{3}-3 z_{c}\right) K-\frac{1}{36}\left(2 z_{c}^{3}-5 z_{c}\right) S^{2}\right\} \sigma\right]
$$

whereby $W$ is the value of the portfolio invested in bitcoin; $z_{c}$ is the critical value for the probability $(1-\alpha)$ and -1.96 for a $95 \%$ probability; $\mu$ is the mean return for bitcoin; $\sigma$ is the standard deviation of bitcoin returns; $S$ is skewness of bitcoin returns; $K$ is excess kurtosis of bitcoin returns. The skewness and kurtosis of bitcoin returns, $R_{t}$, are defined as follows: 


$$
\begin{gathered}
S=\frac{1}{T} \sum_{t=1}^{T}\left(\frac{R_{t}-\bar{R}}{\sigma}\right)^{3} \\
K=\frac{1}{T} \sum_{t=1}^{T}\left(\frac{R_{t}-\bar{R}}{\sigma}\right)^{4}-3
\end{gathered}
$$

After computing each volatility regime's MVaR, we can then compute their modified Sharpe ratios which serve as a measure for returns per unit of higher moment risks:

$$
\text { Modified Sharpe Ratio }=\left(R_{\mathrm{t}}-r_{\mathrm{f}}\right) / \mathrm{MVaR}
$$

whereby $r_{f}$ is the risk-free rate (see footnote (10)).

When comparing MVaR and modified Sharpe ratios across the two regimes, it is apparent that the risk-return tradeoff deteriorates significantly for investors when transitioning from $s_{t}=1$ to $s_{t}=2$. The distinct risk-return environments of the two regimes thus provide an empirical laboratory for gauging the behaviors of the heterogeneous agents in (11) and for making cross-regime comparisons.

\section{Estimation results}

This section estimates the behavioral heterogeneity framework in (11) using the Markov regime-switching approach outlined in (12) through (17) and discusses the empirical implications of its findings on the stock price dynamics of bitcoin. A convenient feature of the model in (11) is its tractability and that it has been formulated to examine fundamentalists' behavior in terms of deviations between fundamental factors with their long-run trajectories. Since risk preferences, forward-looking expectations and, consequently, behavioral trading patterns, can differ between low and high regimes of bitcoin price volatility, it is also advantageous to estimate (11) using the regime-switching framework outlined herein in order to allow for agents to switch between trading behaviors, conditional on their demand functions, in order to allow for cross-regime comparisons.

Table 3 shows coefficient estimates for (11) for the low $\left(s_{t}=1\right)$ and high $\left(s_{t}=2\right)$ volatility regimes, respectively, for each of the four models corresponding with the factor, $\mathrm{F}$, that is used to gauge the behavior of fundamentalists; miners' revenue ("Model 1"), unique addresses ("Model 2"), number of transactions ("Model 3"), and median fee per transaction ("Model 4"), respectively. Each of these fundamental factors serve as important components within bitcoin's microstructure whereby rises (declines) in any of these factors is generally a positive (negative) indication for the fundamental value of bitcoin. As the demand for bitcoin rises, ceteris paribus, we naturally expect to see a rise in the levels of these fundamental factors.

The theoretical compositions of the demand functions for the heterogeneous agents bears empirical implications on the price dynamics of bitcoin. This is observable from the structure of (11) given the coefficient delineations stemming from the unsimplified model in (8); for mean-variance optimizers, $\beta_{1}=\theta$, it is expected that rises (declines) in their demand for bitcoins leads to a positive (negative) autocorrelation pattern in bitcoin returns. Theoretically, $\beta_{1}$ is expected to be positive and significant-consistent with the notion that investors are averse towards volatility risk and that they demand a positive risk premium 
to hold risky assets. In the case of speculators, $\beta_{3}=-\psi(\theta)$, trend chasing behavior, buying when past returns are positive and selling when they are negative, is confirmable if the coefficient $\beta_{3}$ is positive and significant. The behavior of such traders leads to a negative autocorrelation pattern in bitcoin returns. In the case of fundamentalists, $\beta_{4}=-\pi(\theta)$, trading with fundamentals $\left(\mathrm{F}_{i}>\tilde{F}_{i}\right)$ is confirmable if the coefficient $\beta_{4}$ is positive and significant; behavior that leads to a negative autocorrelation pattern in bitcoin returns. Trading against fundamentals $\left(\mathrm{F}_{i}<\tilde{F}_{i}\right)$ is akin to contrarian-type trading and leads to a positive autocorrelation pattern in bitcoin returns.

As discussed, the low volatility regime, $s_{t}=1$, comprises more of the overall sample (as is shown in Figs. 5 and 7) and reflects an investment environment that is less volatile and which provides a more favorable risk-return tradeoff for investors relative to the high volatility regime, $s_{t}=2$. For the low volatility regime, and for all the four models, there is consistent support for the presence of mean-variance optimizers and a positive risk premium for holding bitcoin. This is evidence of a positive risk-return tradeoff in the context of Merton (1980) and is a finding that contrasts sharply with the negative risk-return tradeoff typically observed when examining the time series returns of conventional asset classes such as equities or index funds. ${ }^{10}$ This suggests that bitcoin returns in the low volatility regime sufficiently provide a premium to compensate risk-averse investors for its volatility risk. ${ }^{11}$

Speculative trading pressure is unanimously observed in the low volatility regime from the coefficient $\beta_{3}$. Its negative sign for all four of the models reveals that speculators engage in 'bandwagon behaviors' and buy bitcoins during recent price appreciations and sell during recent price declines. The negative sign for $\beta_{3}$ indicates that their trading behavior leads to a negative autocorrelation pattern in bitcoin returns; recall from (8) that this type of trend chasing behavior results in a positive value for the parameter $\psi$ and, consequently, a negative value for $\beta_{3}$ since $\beta_{3}=-\psi(\theta)$. The extent of the negative autocorrelation partially depends on the level of the conditional variance; this can be inferred from the term $-\psi\left(\theta \sigma_{t}^{2}\right)\left(r_{t-1}\right)$ from (8) which captures speculators' demand for bitcoins and their market impact.

The positive and statistically significant sign for the coefficient $\beta_{4}$ for the low volatility regime for Models 2 and 3, indicates that fundamentalists are trading against bitcoin fundamentals; they are buying when $\mathrm{F}_{i}<\tilde{F}_{i}$ and selling when $\mathrm{F}_{i}>\tilde{F}_{i}$. From (8), it is shown that contrarian behavior among this group of investors results in a negative value for the parameter $\pi$ and a positive value for the coefficient $\beta_{4}$ since $\beta_{4}=-\pi(\theta)$. This induces a positive autocorrelation pattern in bitcoin returns; this can be inferred from the term $-\pi\left(\theta \sigma_{t}^{2}\right)\left(\mathrm{F}_{i, t-1}-\tilde{F}_{i, t-1}\right)$ from (8) which captures fundamentalists' demand for bitcoins and their market impact.

\footnotetext{
10 The behavioral heterogeneity framework in (11) collapses to the Merton (1980) intertemporal capital asset pricing model when we constrain all coefficients, with the exception of $\beta_{1}$, to zero; $r_{t}=\beta_{1} \sigma_{t}^{2}$. When this asset pricing model is tested with returns, $r_{t}$, of conventional asset classes, $\beta_{1}$, the parameter for risk aversion, is typically found to be either negative and significant or statistically zero. This implies a negative relation between $r_{t}$ with its conditional volatility, $\sigma_{t}^{2}$. The 'volatility feedback hypothesis' or 'leverage effect,' two postulations often times used synonymously, are usually evoked to reconcile this finding (Black 1976; Campbell and Hentschel 1992; French et al. 1987).

11 Using a Markov regime-switching framework to regress bitcoin returns solely against its conditional variance, estimated from the EGARCH in (10), shows a positive linkage between returns and volatility in the low volatility state and a weak relation in the high volatility state (results not tabulated for brevity but available upon request).
} 
The results for the high volatility regime, which is associated with a deterioration in the risk-return tradeoff relative to the low volatility regime, reveal that the trading impact of mean-variance optimizers all but dissipate; the coefficient $\beta_{1}$ is positive and weakly significant at the $10 \%$ level for Models 1, 2 and 3, respectively. As in the low volatility regime, the high volatility regime also shows evidence of speculators (as evidenced by the coefficient $\beta_{3}$ ) who buy (sell) during recent price rises (declines).

Fundamentalists in this high volatility regime trade with fundamentals; the coefficient $\beta_{4}$ is negative and statistically significant for all models (with the exception of "Model 3"). Thus, during this regime, they buy bitcoins when $\mathrm{F}_{i}>\tilde{F}_{i}$ and sell when $\mathrm{F}_{i}<\tilde{F}_{i}$.

The economic implications of the findings across the two regimes are as follows; first, the expected returns arising from the high volatility regime are insufficient to satisfy the risk aversions of mean-variance optimizers and to compensate for the accentuated levels of risks they are exposed to. Second, speculators are observable in both regimes; they exhibit trend chasing behavior and this serves as a cautionary note to prospective bitcoin investors and vendors because, at any time, bitcoin's price can drastically change even in the absence of changes in its fundamentals because of herding behaviors which may or may not be purely rational. Third, fundamentalists exhibit heterogeneity in their trading behavior across regimes; their contrarian-like behavior during periods of mild price fluctuations may reflect their anticipation of a correction in bitcoin's market price. Conversely, they trade with fundamentals during exuberant periods to capitalize on large price upswings.

\section{Concluding remarks}

Is bitcoin a modern-day Dutch tulip mania? Departing from broad speculative discussions and relying on empirical means to answer this question, we realize that it is too premature to soundly conclude anything. Satoshi Nakamoto, the unknown architect behind bitcoin and its reference implementation, has stated "...in a few decades when the reward gets too small (for miners), the transaction fee will become the main compensation for nodes. I am sure that in 20 years there will either be very large transaction volume or no volume..." 12

Perhaps none of us, even its creator, know the exact fate of bitcoin or cryptocurrencies at large. A good starting point in our discussions, however, is defining the forces that drive its price variations. Since bitcoin and other cryptocurrencies are a recent phenomena, we only have a few years of time series to examine, which explains why empirical research is now emerging. One of the recurrent themes of this research is that bitcoin prices appear largely detached from familiar economic variables or other sources of aggregate market risk. Any empirical discernment of statistical relations between bitcoin prices and other factors are purportedly unstable across time, leading empiricists to conclude that bitcoin prices cannot be explained or are irrational.

This paper departs from the usual route taken in empirical literature thus far which seeks to regress bitcoin returns against economic or technological factors that potentially underlie its price movements. Since bitcoin is such an unusual asset, it is conceivable that its microstructure characteristics are driven by investors and a clientele base that is inherently distinct from what is usually found in other asset classes. Since risk aversions of such

\footnotetext{
12 Quotes from Satoshi Nakamoto are publicly available here: http://satoshi.nakamotoinstitute.org/quotes/ bitcoin-economics/.
} 
investors differs from those of traditional investors, it is not a complete surprise that bitcoin's prices appear econometrically detached from established economic variables.

Instead, this paper proposes an asset pricing model that captures the heterogeneity in the behavioral trading patterns of three types of agents: mean-variance optimizers, speculators and fundamentalists, respectively. The model allows for estimating the impacts of these investors during low and high bitcoin price volatility regimes. It shows evidence in favor of behavioral heterogeneity as a driving force of bitcoin price fluctuations. The fractions of agents engaging in one strategy over another shows variation during low and high bitcoin price volatility regimes. Speculators consistently show 'bandwagon behaviors' in both regimes and tend to buy during recent bitcoin price appreciations and sell during recent price declines. Their strong presence in bitcoin markets serves as a cautionary note for investors and vendors who accept bitcoins. This is because the strong speculative pressures these speculators exert can lead to large swings in prices at any given time. Finally, it is remarkable to observe the duality in the behavior of fundamentalists; during low price volatility regimes they exhibit contrarian-type behaviors while during high volatility price regimes they behave more like fundamentalists.

An econometric contribution of the framework laid forth in this paper is that it can tractably be applied to virtually any asset class for which prices are observable. The Markov regime-switching framework which implements the proposed framework allows testing for the presence of behavioral heterogeneity across volatility regimes. Doing so permits crossregime comparisons to test whether any duality exists between trading behaviors. The demand function proposed herein for fundamentalists can also be modified by empiricists to accommodate virtually any fundamental factor which theoretically serves as a measure of fundamental value.

\section{References}

Aalborg HA, Molnar P, Vries JE (2019) What can explain the price, volatility and trading volume of bitcoin? Finance Res Lett 29:255-265

Ardiar D, Bluteau K, Ruede M (2019) Regime changes in bitcoin GARCH volatility dynamics. Finance Res Lett (forthcoming)

Balcilar M, Bouri E, Gupta R, Roubaud D (2017) Can volume predict bitcoin returns and volatility? A quantiles-based approach. Econ Model 64:74-81

Bange MM (2000) Do the portfolios of small investors reflect positive feedback trading? J Financ Quant Anal 35(2):239-255

Baur DG, Dimpfl T (2018) Asymmetric volatility in cryptocurrencies. Econ Lett 173:148-151

Baur DG, Hong K, Lee AD (2018) Bitcoin: medium of exchange or speculative bubble? J Int Financ Mark Inst Money 54:177-189

Black F (1976) Studies of stock price volatility changes. In: Proceedings of the 1976 meetings of the business and economic statistics, American Statistical Association, pp. 177-181

Böhme R, Christin N, Edelman B, Moore T (2015) Bitcoin: economics, technology, and governance. J Econ Perspect 29(2):213-238

Bouri E, Jalkh N, Molnár P, Roubaud D (2017) Bitcoin for energy commodities before and after the December 2013 crash: diversifier, hedge or safe haven? Appl Econ 49(5):5063-5073

Brandvold M, Molnar P, Vagstad K, Christian O, Volstad A (2015) Price discovery on bitcoin exchanges. J Int Financ Mark Inst Money 36:18-35

Campbell JY, Hentschel L (1992) No news is good news: an asymmetric model of changing volatility in stock returns. J Financ Econ 31(3):281-318

CoinMarketCap (2020) Cryptocurrency market capitalizations. Publicly available online: https://coinm arketcap.com/. Accessed 1 Mar 2020

Cutler DM, Poterba JM, Summers LH (1990) Speculative dynamics and the role of feedback traders. Am Econ Rev Pap Proc 80(2):63-68 
French KR, Schwert GW, Stambaugh RF (1987) Expected stock returns and volatility. J Financ Econ 19(1):3-29

Gregoriou GN, Gueyie JP (2003) Risk-adjusted performance of funds of hedge funds using a modified Sharpe ratio. J Wealth Manag 6(3):77-83

Guo M, Ou-Yang H (2014) Feedback trading between fundamental and non-fundamental information. Rev Financ Stud 28(1):247-296

Hamilton JD (1988) Rational-expectations econometric analysis of changes in regime: an investigation of the term structure of interest rates. J Econ Dyn Control 12(2-3):385-423

Hamilton JD (1989) A new approach to the economic analysis of nonstationary time series and the business cycle. Econometrica 57(2):357-384

Hamilton JD (1990) Analysis of time series subject to changes in regime. J Econom 45(1-2):39-70

Hamilton JD (2017) Why you should never use the Hodrick-Prescott filter. National Bureau of Economic Research, working paper no. w23429

Hodrick RJ, Prescott EC (1997) Postwar US business cycles: an empirical investigation. J Money Credit Bank 29(1):1-16

Hou Y, Li S (2014) The impact of the CSI 300 stock index futures: positive feedback trading and autocorrelation of stock returns. Int Rev Econ Finance 33:319-337

Katsiampa P (2017) Volatility estimation for bitcoin: a comparison of GARCH models. Econ Lett $158: 3-6$

Kinnunen J (2014) Risk-return trade-off and serial correlation: do volume and volatility matter? J Financ Mark 20:1-19

Kirchler M, Huber J (2007) Fat tails and volatility clustering in experimental asset markets. J Econ Dyn Control 31(6):1844-1874

Koutmos D (2018a) Bitcoin returns and transaction activity. Econ Lett 167:81-85

Koutmos D (2018b) Liquidity uncertainty and bitcoin's market microstructure. Econ Lett 172:97-101

Li X, Wang CA (2017) The technology and economic determinants of cryptocurrency exchange rates: the case of bitcoin. Decis Support Syst 95:49-60

Lo AW, MacKinlay AC (1990) An econometric analysis of non-synchronous trading. J Econom 45(1-2):181-211

Mandelbrot B (1963) The variation of certain speculative prices. J Bus 36(4):394-419

Merton RC (1980) On estimating the expected return on the market: an exploratory investigation. J Financ Econ 8(4):323-361

Nakamura Y (2015) Mean-variance utility. J Econ Theory 160:536-556

Nelson DB (1991) Conditional heteroskedasticity in asset returns: a new approach. Econometrica 59(2):347-370

Nofsinger JR, Sias RW (1999) Herding and feedback trading by institutional and individual investors. J Finance 54(6):2263-2295

Panagiotidis T, Stengos T, Vravosinos O (2018) On the determinants of bitcoin returns: a LASSO approach. Finance Res Lett 27:235-240

Phillips KL (1991) A two-country model of stochastic output with changes in regime. J Int Econ 31(1):121-142

Pieters G, Vivanco S (2017) Financial regulations and price inconsistencies across bitcoin markets. Inf Econ Policy 39:1-14

Ravn MO, Uhlig H (2002) On adjusting the Hodrick-Prescott filter for the frequency of observations. Rev Econ Stat 84(2):371-376

Sentana E, Wadhwani S (1992) Feedback traders and stock return autocorrelations: evidence from a century of daily data. Econ J 102(411):415-425

Shen CH (1994) Testing efficiency of the Taiwan-US forward exchange market-a Markov switching model. Asian Econ J 8(2):205-216

Shiller RJ (1984) Stock prices and social dynamics. Brookings Pap Econ Act 2:457-510

Shiller RJ (2000) Irrational exuberance. Princeton University Press, Princeton

Signer A, Favre L (2002) The difficulties of measuring the benefits of hedge funds. J Altern Invest $5(1): 31-41$

Thies S, Molnar P (2018) Bayesian change point analysis of bitcoin returns. Finance Res Lett 27:223-227

Wan D, Yang X (2017) High-frequency positive feedback trading and market quality: evidence from China's stock market. Int Rev Finance 17(4):493-523 
Zhang XM, Zhang L (2015) How does the internet affect the financial market? An equilibrium model of internet-facilitated feedback trading. MIS Q 39(1):17-38

Publisher's Note Springer Nature remains neutral with regard to jurisdictional claims in published maps and institutional affiliations. 